\title{
Polycyclic Aromatic Hydrocarbons Separation from Oil-Contaminated Soil Using Supercritical and Subcritical Water
}

\author{
Motamedimehr S, Gitipour S* and Ardestani M
}

School of Environment, College of Engineering, University of Tehran, Tehran, Iran

*Corresponding author: Gitipour S, School of Environment, College of Engineering, University of Tehran, Tehran, Iran, Tel: +98912313 4979, E-mail: gitipour@ut.ac.ir

Citation: Motamedimehr S, Gitipour S, Ardestani M (2018) Polycyclic Aromatic Hydrocarbons Separation from Oil-Contaminated Soil Using Supercritical and Subcritical Water. J Environ Pollut Control 1(1): 106. doi: $10.15744 / 2639-9288.1 .106$

Received Date: June 27, 2018 Accepted Date: September 12, 2018 Published Date: September 14, 2018

\begin{abstract}
Finding an environmental-friend and an affordable method to remove contaminated soils from polycyclic aromatic hydrocarbons (PAHs) is now an attractive field for researchers. PAHs are slightly soluble, thus hardly dissolve in organic compounds, and also biological and chemical degradation processes are not effective to remove them, and the process of extracting these pollutants from soil is a complex process. Super-critical fluid extraction is an innovative process in the field of contaminated soil treatment. Extraction with super-critical fluid is a simple and rapid extraction process which uses supercritical fluids as solvents. This method addresses extraction methods using supercritical and subcritical fluid. The results showed that the supercritical fluid process is very suitable to remove the pollutants such as PHCs, PAHs, PCBs, dioxins, Furans, phenols, Chlorophenols, insecticides, metals and radioactive substances. The supercritical fluid extraction using $\mathrm{CO}_{2}$ also has the ability to effectively eliminate organic and inorganic compounds present in different contaminated soils. Moreover, this method is more economical for polluted soil treatment compared to other available methods. On the other hand, using this method that uses water is environment-friendly and has lower cost and a higher safety level. Research has also shown that pressurized hot water extraction (SWE) is a better way to extract PAHs. In this method, the extraction process can be improved by combining the SWE process with the oxidation process by adding oxidants such as air, oxygen, hydrogen peroxide, etc.

Keywords: Oil contaminated soil; Polycyclic aromatic hydrocarbons; Super and subcritical fluid; Supercritical water oxidation
\end{abstract}

\section{Introduction}

In the past, marine oil spills have caused devastating impacts on both shorelines and seas due to the oil hazardous property of the oil. In 1978, the large oil spill due to the Amoco Cadiz in France released over 223,000 tonnes of light crude oil and 4000 tonnes of bunker oil, contaminating a total shoreline length of $320 \mathrm{~km}$ up to a depth of 20 inches [1]. Failure to remove oil from the shoreline resulted in a long-term contamination, with layers of oil still remained buried in the beach site up to 8 years after the oil spill incident [2]. Similarly, the Exxon Valdez oil spill in 1989, spilled 11 million gallons of crude oil into the sea drifted and damaged up to 1300 miles of shoreline [3]. Despite the efforts in clean-up, only $10 \%$ of the oil was recovered [4]. A study by National Oceanic and Atmospheric Administration (NOAA) showed that more than $87 \mathrm{~m}^{3}$ of oil is still remained in Alaska's sandy soil in the contaminated beaches shoreline as of 2010, breaking down at a rate estimated at $4 \%$ per year [5].

The toxicity of oil spills on contaminated soil is of a great concern especially on the environment, and several groups of researchers have highlight it [6-11] investigated on the toxic effects of petroleum soil contamination of up to $10.57 \%$ on the earthworm, bacteria, and plant. The death rate of earthworms was at $90 \%$ after 7 days at oil content of $2 \%$, while no earthworms survived in the soil contaminated with an oil content of $3 \%$ and more. Likewise, inhibition rate of bacteria is nearly $100 \%$ at petroleum content of $1 \%$. In terms of plant germination at oil content of $3 \%$, the germination inhibition rate of maize and wheat is $51.3 \%$ and $48.4 \%$ respectively. The root growth also showed similar trend whereby higher concentrations of oil inhibit the growth of roots [11]. Similarly, increase in oil concentration from $31 \mathrm{mg} / \mathrm{kg}$ to $1000 \mathrm{mg} / \mathrm{kg}$ was found to vastly decrease the survival rate of earthworm's from $80 \%$ to $33 \%$ after 14 days [8]. In addition, a recent study by Ramadass et al. (2015) also showed that used motor oil concentrations of greater than $3.88 \mathrm{~g} / \mathrm{kg}$ soil caused complete mortality of earthworms [12]. Clearly, it could be seen that the oil spillage on soil greatly impacts the surrounding environments, which highlights the urgent need for effective removal of the oil contaminant from the soil. For the time being, most efforts to clean up the oil spill on soil and shoreline require mechanical and labor-intensive methods as they may be a quick and simple solution to remove oil contaminants [13]. However, there are many disadvantages associated with these methods. For instance, using high-pressure washing to displace oil may destroy the microbial populations, while the chemical sorbents and dispersants may be harsh to the environment. In addition, these mechanical methods 
are tedious, time-consuming and are only capable of removing the oil contaminants up to a certain extent, leaving behind a large amount of oil absorbed in the soil. These conventional first response actions are therefore not able to achieve efficient clean-up of oil spills under a short period of time. Therefore, there is an urgent need to investigate other environmental-friendly remediation methods to remove oil contaminants in soil. Today, there is a variety of technologies available for the remediation of oil-contaminated soil, ranging from widely applied technologies such as solvent extraction and bioremediation to the emerging technologies such as electrokinetic remediation and sonication. The remediation technologies for oil contaminated soil can be classified into biological, chemical, thermal and physicochemical methods.

Exploration, production, transportation and use of oil can affect the environment. Leakage from pipelines, oil wells, underground storage tanks, inappropriate disposal of oil waste and disposing it into the soil are the main sources of soil pollution and, consequently, surface and underground water pollution. Polycyclic aromatic hydrocarbons (PAHs) are created from incomplete burning and thermal decomposition of organic materials. Human and natural causes such as forest fires, volcanoes, vehicle pollution, fossil fuels and oil pollution contaminate the soil with PAHs. The cancerous nature of these pollutants has led to extensive researches to sweep them from the soil [14]. These hydrocarbons should be removed from the soil due to environmental and health hazards, as well as to prevent further contamination of the surface and groundwater [15]. The performance and efficiency of these methods depend on factors such as the amount of oil leakage, depth of penetration of oil in the soil, soil type and also age and surface of contamination. Therefore, different types of purification methods such as extraction with organic solvents, extraction with an aqueous solution, Supercritical and subcritical fluid extraction and biological removal using associated bacteria are used accordingly [16].

PAHs are slightly soluble, thus hardly dissolved in organic compounds, and biological and chemical degradation processes are not effective to remove them. Because of these characteristics, it would be a complex process to extract these pollutants from soil. Temperature, solvent type, moisture and soil characteristics are among the factors influencing the extraction of PAHs from the soil. The presence of various and aliphatic hydrocarbons in the soil is determined using FTIR, Fourier transforms and gas chromatography and mass spectrometry GC-MS. Several processes are used to remove PAH contaminants, but their using expenses are relatively high (Figure 1).<smiles>c1ccc2cc3ccccc3cc2c1</smiles>

(1)<smiles>CC(C)(C)C</smiles>

(6)<smiles>c1ccc2cc3c(ccc4ccccc43)cc2c1</smiles>

(11)

dibenz[a. h]anthracene

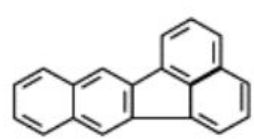

(16)

benzo[k]floranthene

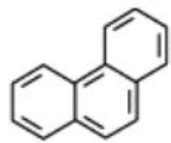

(2)

phenanthrene<smiles>c1cc2ccc3cccc4ccc(c1)c2c34</smiles>

(7)

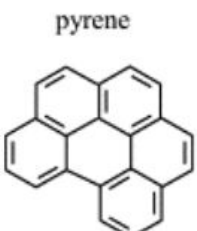

(12)

benzo[ghi]perylene<smiles>c1ccc2c(c1)Cc1ccc3ccccc3c1C2</smiles>

(17)

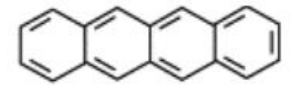

(3)

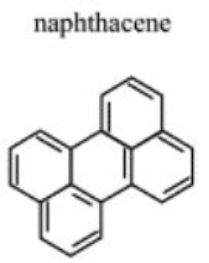

(8)

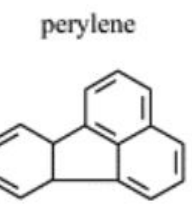

(13)

fluoranthene

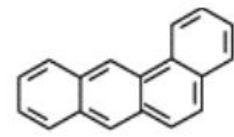

(4)

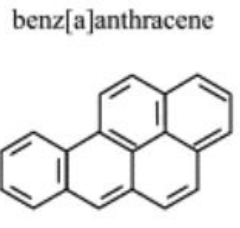

(9)

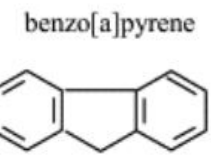

(14)

fluorene

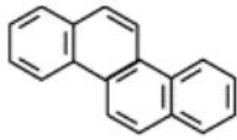

(5)

chrysene<smiles>C1=Cc2cc1cccc1c3c4c(cccc2-3)cccc14</smiles>

(10)

benzo[e]pyrene

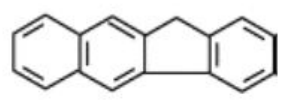

(15)

benzo[b]fluorene

benzo[a]fluorene

Figure 1: Polycyclic aromatic hydrocarbons (PAHs) compounds [17]

Thermal oxidation and excavation are examples of these expensive processes. Besides, biological separation processes need much time. The process of extraction that uses solvents is limited because of high solvent consumption and producing waste streams. However, super-critical fluid extraction is such an innovative process that addresses almost all of these issues (Figure 2).

Here, we address the extraction methods applied using supercritical and subcritical water. 


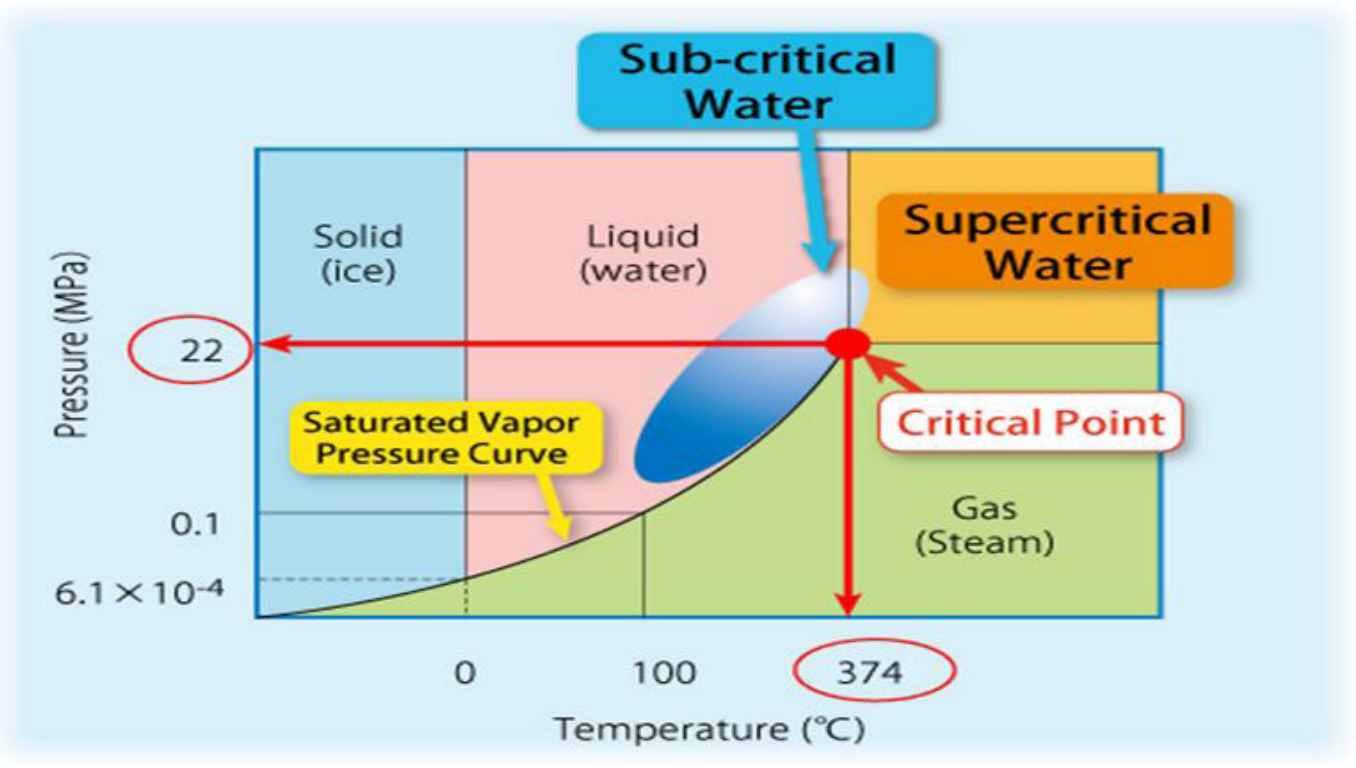

Figure 2: A schematic view of Temperature and pressure range for the sub and supercritical water

\section{Polycyclic aromatic hydrocarbons extraction}

Several methods have been used to extract PAH from solid matrices. Essentially, they can be classified into two subcategories:

Processes using pressurized fluids; (b) Atmospheric pressure processes.

Processes using pressurized fluids are as follows:

\section{Accelerated Solvent Extraction (ASE)}

ASE is a relatively new extraction technique in which organic solvents are used at certain temperatures and pressures. ASE provides faster extraction and needs less solvent volume in compare with classic extraction methods such as Soxhlet extraction. Generally, the pressure and temperature of the extraction, which are the practical parameters of the ASE, affect its efficiency. In addition, the sample matrix also has an effect on the extraction efficiency [18].

\section{Subcritical water extraction (SCWE)}

This process is based on the polarization change in water, which occurs during the temperature rise from ambient to subcritical temperatures $\left(374^{\circ} \mathrm{C}\right)$. To maintain water in the liquid state, the system must operate with normal pressures of 50 to 200 bar. Increasing the temperature to higher than $200{ }^{\circ} \mathrm{C}$ reduces the water dielectric constant. Similarly, the temperature has a similar effect on two other parameters, surface tension, and viscosity [19]. Considering the benefits of hot water properties, the solubility of some PAHs increases up to a maximum of five times.

\section{Supercritical fluid extraction (SFE)}

Supercritical fluid extraction (SFE) is listed as an alternative approach to conventional extraction techniques. A supercritical fluid (SCF) is identified as any combination at temperature and pressure above the critical values (above the critical point), in this area, the fluid properties are between the liquid and gas state. For instance, the fluid density is nearer to liquid phase density, and the viscosity and permeability of the fluid are more similar to the gas phase. Supercritical fluids have zero surface tension and easily enter the solid matrix [20-22]. In a supercritical state, the fluids are highly sensitive to the slightest changes in temperature and pressure, thus it is probable that in a setting of pressure and temperature, the liquid absorbs the pollutant and in another setting, this fluid disposes of the same pollutant [23]. So, pressure and temperature are the two major factors in this process. Supercritical fluid extraction depends on the density of the fluid, which, in turn, can be manipulated by controlling the pressure and temperature of the system. In supercritical fluid extraction method, the extracted contaminants are first dissolved in a supercritical solvent, and then these contaminants are separated from the supercritical solvent by a simple change in pressure and temperature conditions using a separation process. $\mathrm{CO}_{2}$ is the most common SCF, due to its low temperature $\left(31.1^{\circ} \mathrm{C}, 73.8\right.$ times), low cost and non-toxicity [24].

Supercritical fluid extraction (SCFE), on the other hand, uses fluid which is heated and pressurized above the critical point, otherwise known as the supercritical fluid (SCF)([25]. Due to the high temperatures and pressures, SCF exhibits gaseous-liquid properties such as liquid-like density, high diffusivity, low viscosity and no surface tension. [25-27]. The efficiency of SCFE depends greatly on the solubility and mass transfer of the contaminant into the SCF [27]. The most commonly used fluid for SCFE is CO, due to its non-polar nature and liquid solubility characteristics. It is also inexpensive, non-toxic, and vastly available and owns a 
moderate critical pressure and temperature. Other SCFs considered include propane and butane. While the latter SCFs exhibit excellent oil and grease removal from soil and sludge, these fluids are highly flammable that make their use potentially hazardous to human health $[28,29]$ investigated the use of $\mathrm{CO}_{2}$ for the extraction of crude oil from contaminated soil under pressures ranging from $80-120$ bars for temperatures between $40-60^{\circ} \mathrm{C}$, and $200-300$ bars for temperatures between $100-140{ }^{\circ} \mathrm{C}$. The researchers reported that although supercritical $\mathrm{CO}_{2}$ could only remove up to $4 \%$ of crude oil in soil at pressures of 80 bars in the temperature range studied, its efficiency was seen to increase with pressure, reaching up to a maximum of $72.4 \%$ at 300 bars and $100{ }^{\circ} \mathrm{C}$. Other documented works on the use of supercritical $\mathrm{CO}_{2}$ for the remediation of petroleum hydrocarbons include the study by Morselli $e t$ al. (1999) [27]. This study reported that with an addition of $5 \mathrm{v} / \mathrm{v} \%$ of acetone to supercritical $\mathrm{CO}_{2}$ at $80^{\circ} \mathrm{C}$ and pressure of $227 \mathrm{~atm}$, the removal efficiency of crude oil from soil increased from $60 \%$ to $75 \%$ without the acetone addition. The results suggest that the acetone exerts a swelling action on the soil which helps to pry open the interlayer of the soil structure. Likewise, Geranmayeh et al. (2012) also used $\mathrm{CO}_{2}$ for the extraction of oil from contaminated soil from the Pazanan II production unit site in Gachsaran, Iran. In this study, the optimum operating parameters such as pressure, temperature, flow rate and duration were obtained to optimize the removal of the contaminant [30].

\section{Oxidation in extraction process}

In any case, the extraction stage as a single treatment technology is not the definitive solution for PAH-contaminated soils. However, the degradation of polycyclic aromatic hydrocarbons makes it extremely important.

Bioremediation of infected sites may be an efficient and economically attractive option as a single technology. However, the kinetics of the process is very slow due to the limited range of soil contaminant molecules in most cases. Similarly, soil bio improvisation is considered [31-36].

\section{Advantages of chemical oxidation of soil}

- The required time for cleaning the soil is made significantly shorter.

- The chemical oxidation conditions (such as pressure, temperature, the addition of solid solvents, etc.) can be changed. Therefore, existing contaminator molecules are available for chemical reactions in order to biological correction.

- Chemical oxidation is relatively insensitive to external imbalances (such as pollution load, temperature changes, etc.).

- Chemical oxidation can be combined with the extraction process so that the PAH decomposition in the extraction fluid is performed.

\section{Disadvantages of the oxidation stage}

- This technology is not economic compared to environmental processes.

- If organic solvents are used (for example in the extraction stage), they should be used carefully and recycled.

- If the extreme conditions of low temperature and pressure are used, there is a potential for reduction of chemical reactions rate.

- Sometimes, the process may not be economical due to the number of chemicals required.

Subsequently, this study will present and review, several projects and plans accomplished in this area.

\section{Studies on extraction methods by supercritical and subcritical water}

\section{Extraction of fluid under pressure}

\section{Pressurized hot water extraction (PHWE method) from phthalic anhydride and benzoic acid from petrochemical waste using supercritical liquid extruder and a central composite design for optimization}

The pilot plan is used to obtain optimal conditions for the semi-continuous extraction of PA and BA from their combination with benzoic acid, maleic acid, phthalic acid, phthalic anhydride, aldehydes, phthalimide, Toufic acid, and some minor impurities [37].

Variables such as pressure (220-260 bar), temperature $\left(160-140{ }^{\circ} \mathrm{C}\right)$, dynamic time (5 to 45 minutes) and flow velocity $(0.2-1 \mathrm{~mL} /$ min) were used. The Molten phthalic acid sample contains PA, toluic acid, BA, phthalimide, maleic acid (MA), aldehydes, phthalic acid and some minor impurities.

MPA solid and hard samples were broken to 40 to 60 sizes (particle diameter about 0.3-0.55 $\mathrm{mm}$ ) to increase the contact surface and mass transfer of the Analyte in the PHWE process. The prepared MPA sample $(\sim 3 \mathrm{~g})$ is transferred to a $10 \mathrm{ml}$ cylindrical stainless steel extraction chamber. The PHWE method is dynamically performed by passing the water at different flow rates, temperatures, pressures and time through the extraction chamber. The remaining water in the chamber, the pipe and the recycle pressure regulator is eliminated by cleaning the PHWE system with $\mathrm{CO}_{2}$ at the end of each extraction. Ethanol is injected into the tube so that it washes the tube each time the pipe system is blocked. The extraction solvent is evaporated at $80^{\circ} \mathrm{C}$ and volumes were made to $10 \mathrm{ml}$ with a solution of $2.50 \mathrm{~g}$ per naphthalene liter in a volumetric flask, in acetonitrile. [38-40].

The results showed that at $140{ }^{\circ} \mathrm{C}$, the pressure, extraction time and solvent flow rate were $118 \mathrm{bar}, 27 \mathrm{~min}$, and $0.2 \mathrm{ml} / \mathrm{min} \mathrm{respec}$ tively for 100\% yield of PA and these values are $118 \mathrm{bar}, 29 \mathrm{~min}$ and $0.9 \mathrm{ml} / \mathrm{min}$ for $98 \%$ extraction of BA. Moreover, the maximum selection of PHWE at $100^{\circ} \mathrm{C}$ was obtained as $220 \mathrm{bar}, 5 \mathrm{~min}$, and $0.2 \mathrm{ml} / \mathrm{min}$ (Figure 3 ). 


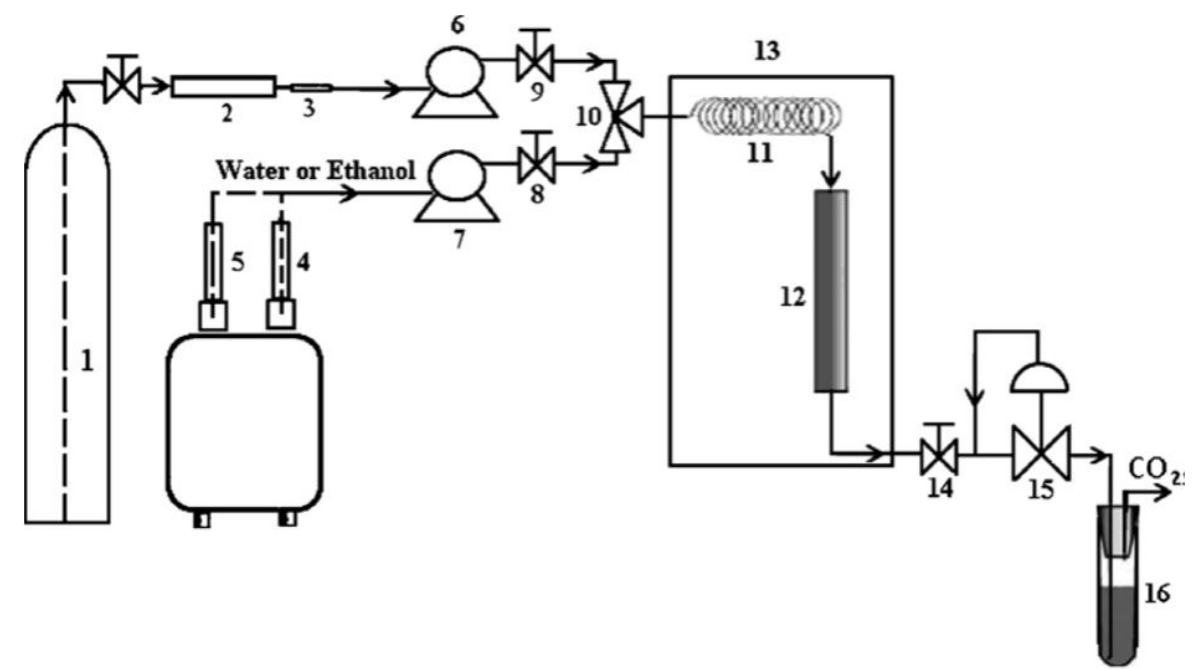

Figure 3: PHWE coordinates diagram: (1) $\mathrm{CO}_{2}$ tank; (2) molecular sieve filter; (3) ss 2_m particle size filter; (4) water tank; (5) ethanol tank; (6) $\mathrm{CO}_{2}$ transfer pump ; (7) high pressure piston pump; $(8,9,14)$ double-sided valve; (10) triple valve;

(11) preheat wiring; (12) extraction chamber; (13) thermal furnace; (15)Back pressure regulator and (16) sampling tank

\section{Hot water / steam Extraction under pressure from polychlorinated dibenzofurans and naphthalene from industrial soil}

Pressurized hot water extraction (PHWE), herein is described as water extraction and steam extraction (PCDFs) in the sand at various conditions water at 10 or 50 atmospheres (excluding 50 atmospheres and $200{ }^{\circ} \mathrm{C}$ ) is in the gaseous phase [41]. And in 250 atmospheres at all temperatures, except at $400{ }^{\circ} \mathrm{C}$ which is located at the supercritical point, is liquid. The extraction was started by the first water pumping through the extractor chamber at a constant speed of about 1 milliliter per minute and the pressure regulator was adjusted to match the desired pressure. The total extraction time was about 30 minutes, with a volume of about $30 \mathrm{ml}$ (28 to $35 \mathrm{ml})$. $\mathrm{ml})$.volume of about $30 \mathrm{ml}$ (28 to $35 \mathrm{ml}$ ) (Figure 4 ).

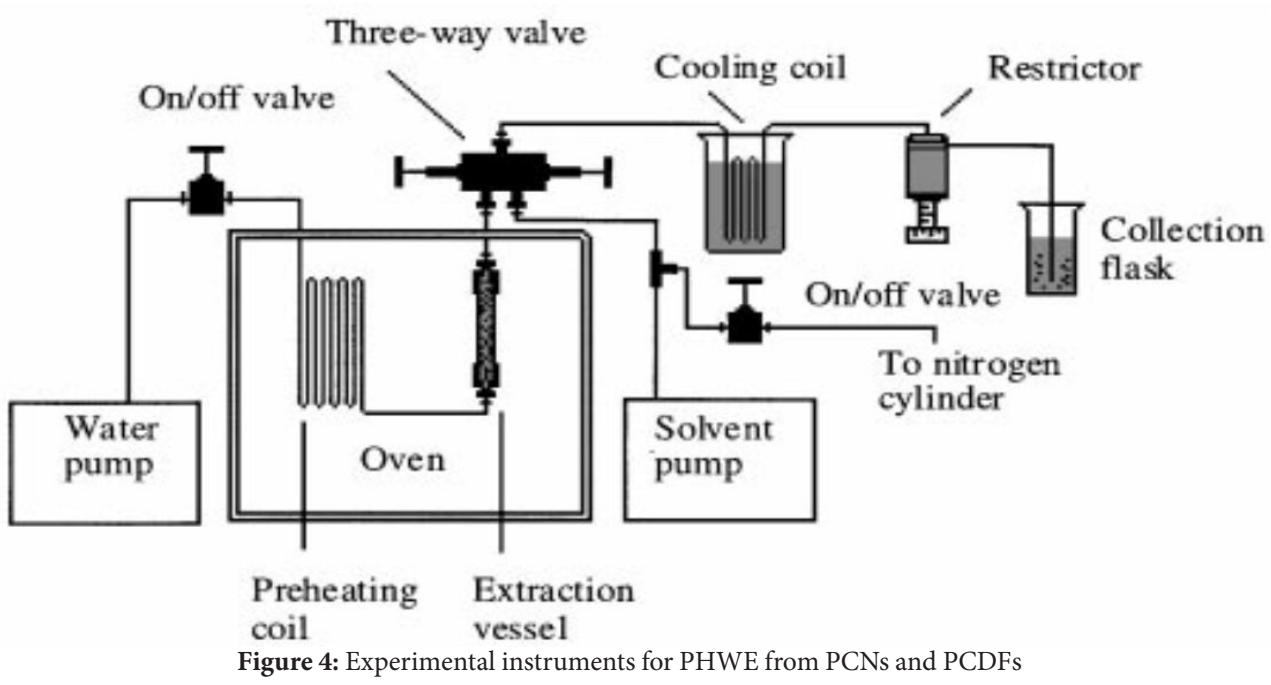

The results showed that optimal extraction conditions for these compounds were found to be between 300 and $350{ }^{\circ} \mathrm{C}$. The highest extraction efficiency was achieved in the gas phase at 50 atmospheres. With Steam at $300{ }^{\circ} \mathrm{C}$ and 50 horsepower extraction (compared to Soxhlet extraction), polychlorinated naphthalenes (PCNs) were achieved from the industrial soil. Additionally, compared to the values obtained from an international comparative study, Soil toxicity by PCDFs is reduced by at least $90 \%$ using PHWE.

\section{Extraction of subcritical water}

Restoration of PAH-contaminated soils by extraction using subcritical water: The correction of soil contaminated with polycyclic aromatic hydrocarbons (PAHs) has been investigated through extraction using subcritical continuous flow water [42]. (Islam et al. 2012). Water temperature from 100 to $300^{\circ} \mathrm{C}$, extraction time from 15 to 60 minutes and flow rate in the range of 0.5 to $2.0 \mathrm{ml} / \mathrm{min}$ were investigated to specify their effect on removal efficiency of PAHs.

Subcritical water (SCW) extruder containing a 10-mL reactor, consisting of a water tank, a high-pressure pump, a preheater reactor, a thermometer, a pressure regulator and a separator were used (Figure 5). 


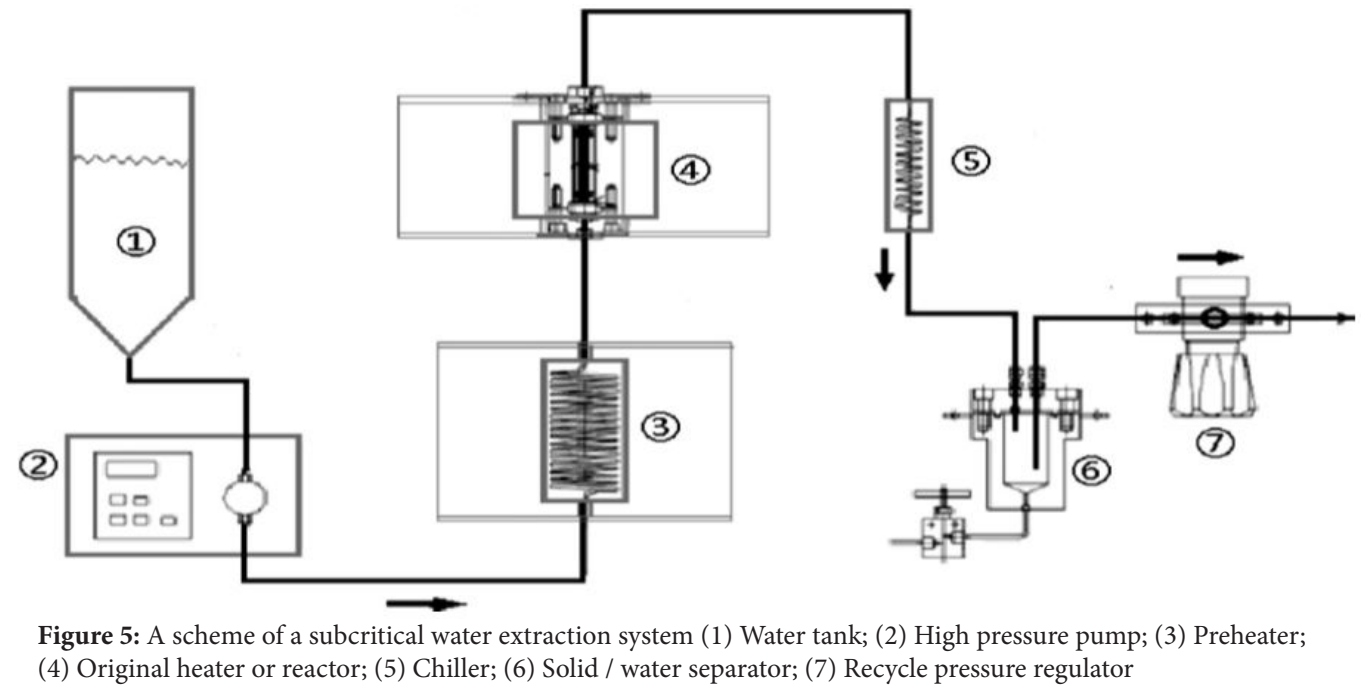

Distilled water is used as a solvent for extraction. Before using distilled water, helium gas was purged for 30 minutes to remove the dissolved oxygen because the water-soluble oxygen causes the oxidation of PAH in water at subcritical conditions [43]. $8 \mathrm{~g}$ of highly contaminated soil is transferred to the reactor and purified distilled water flows through the preheater and the reactor at a rate of $2.0-0.5 \mathrm{ml} / \mathrm{min}$. Pressure ranges from 50 to 100 bar at room temperature to reach the desired temperature and maintain a constant pressure of 100 times. The water is transferred through the extraction reactor to the post-flow, purge vertically to prevent filter clogging and lighter materials extraction. At high temperatures, water acts as an organic solvent which can dissolve PAHs.

The results showed that extraction efficiency depends mainly on the temperature and extraction time. There is also a significant dependence on flow rates. The results showed that increasing water temperature causes an increase in the phenanthrene, fluoranthene, and pyrene adsorption. More than $95 \%$ of extracted phenanthrene, fluoranthene, and pyrene from contaminated soil are done at $300{ }^{\circ} \mathrm{C}$ for 30 minutes and $250{ }^{\circ} \mathrm{C}$ for 60 minutes with a constant pressure of 100 bar. However, naphthalene was almost exclusively extracted at a relatively low temperature of $150{ }^{\circ} \mathrm{C}$ and extraction time of over 30 minutes and a pressure of 100 bar. The subcritical water flow rate of $0.5 \mathrm{ml} / \mathrm{min}$ is recommended. The extraction of PAHs has been strongly dependent on water temperature since rising the temperature the dielectric constant (polarity) of water. These results indicate that contaminated soils with chemicals such as PAHs can be easily purified using pure, high-temperature exhaust without modification.

\section{Extraction of selected categories of polar, relatively polar and nonpolar magmatic wastes from hydrocar- bon wastes using subcritical water}

Liquid water at 250 or $300^{\circ} \mathrm{C}$ efficiently extracts PAHs but does not extract high molecular weight alkanes (eg, CO $\mathrm{CO}_{2}$. Little extraction of high-molecular-weight alcohols was achieved only with super-heated steam $\left(250\right.$ and $300^{\circ} \mathrm{C}$ at 5 atmospheres). The extraction of phenols, alkylbenzenes, PAHs, and alkanes is simply done by a ch the water temperature $\left(300-50{ }^{\circ} \mathrm{C}\right)$ or pressure $(5-100$ amperes) [44] (Figure 6).

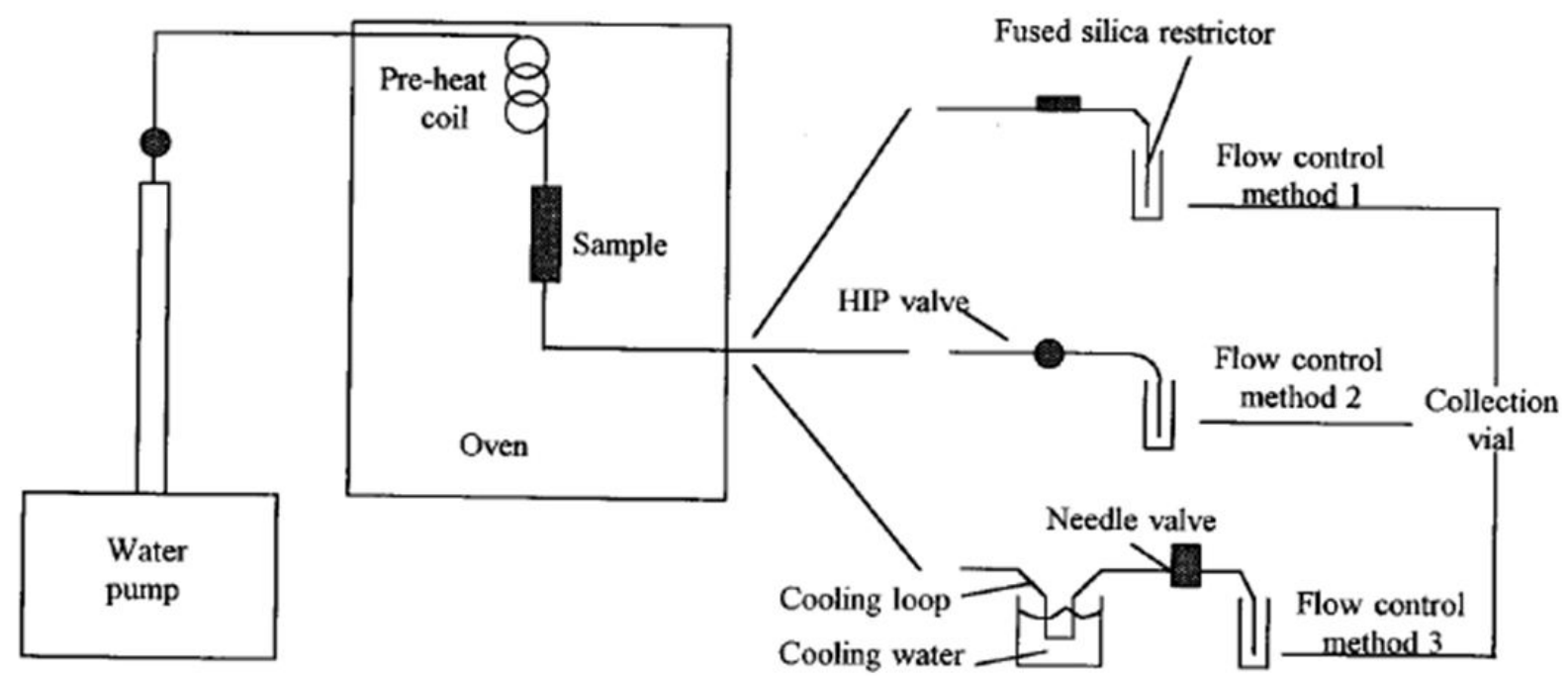

Figure 6: A Summary chart of the subcritical water extraction and collection system 
Journal of Environmental Pollution and Control

The soil sample contained PAHs and alkanes, petroleum sewage sludge including phenols and alcoholic phenols and water sludge include BTEX (benzene, toluene, ethylene benzene and xylene) and a very high level ( $6 \% \mathrm{w} / \mathrm{w})$ of branched hydrocarbons (C10 C17). First, the extraction chamber was completely filled with sand and then targeted analytes were located on the sand. The water was dissolved in nitrogen for 1-2 hours to remove its oxygen. The pump operates at constant pressure mode (or in a steady flow for steam extraction) to supply water to the extraction chamber. The water flow rate is $1 \mathrm{ml} / \mathrm{minute}$. The solvent evaporates at temperatures above 200 to $300{ }^{\circ} \mathrm{C}$ during the extraction. So, the bottles are cooled with ice water to prevent evaporation of the solvent. Both the inlet and outlet valves return from the chamber while the GC oven is heated to the desired temperature. Therefore, during the heating time, typically the water is maintained for $1,2,3,4,5$, and 7 minutes at 50,100, 150, 200, 250 and $300^{\circ} \mathrm{C}$. The wastewater temperature reaches $250{ }^{\circ} \mathrm{C}$ for only 1.5 minutes after the oven. A set of extracted analytes is transferred to a glass bottle of $22 \mathrm{ml}$ containing $3 \mathrm{ml}$ of collector solvent (methylene chloride) by placing the output flow limiter (flow control device). The results indicate the recovery of all target analytes by extraction of subcritical waters (generally 90 to 120 percent).

\section{Ability to recover oil from contaminated soil at oil leakage site using subcritical water extraction technology}

In this study, a total hydrocarbon oil (TPH) present in soil is considered as the target pollutant(Islam et al. 2017). The concentration of oil in the contaminated soil was $4.08 \%$ of its weight $(40832 \mathrm{mg} / \mathrm{kg})$. The $\mathrm{pH}$ of the contaminated soil was 8 and the average moisture content was $26 \%$. Experimental condition was as follows: extraction time 90 minutes at $260{ }^{\circ} \mathrm{C}$ in absolute pressure of $8 \mathrm{MPa}$ and the water-to-oil ratio of 3: 1 . After extraction, the oil removal efficiency was about $86 \%$ of the remaining soil and recycled almost $39 \%$ of the oil. The equipment can operate up to $15 \mathrm{MPa}$ and $300^{\circ} \mathrm{C}$ conditions (Figure 7).

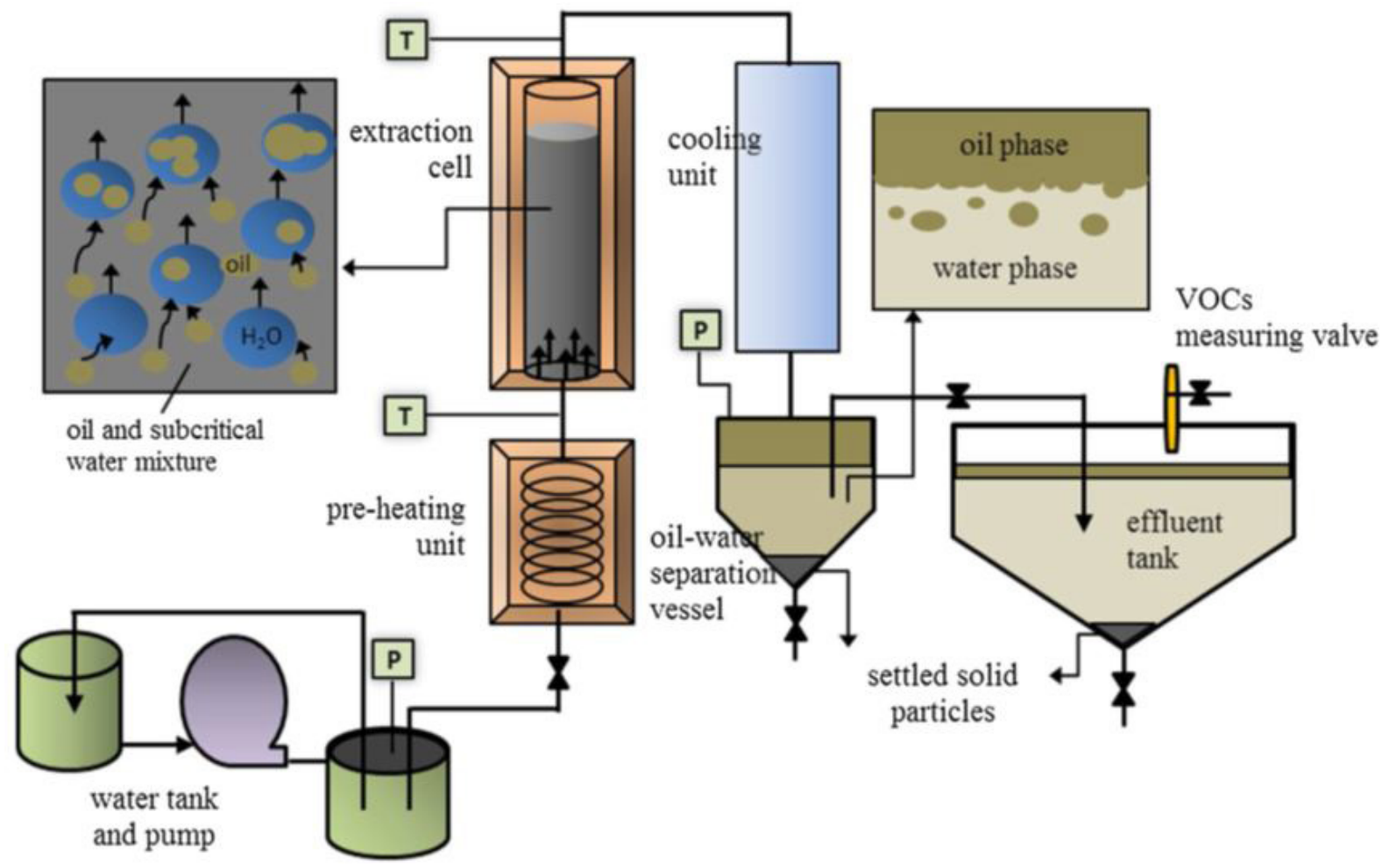

Figure 7: An overview of the SWE device and the dissolving mechanism and subcritical oil separation

A specific amount of water (4.5 liters, water to soil ratio being 3: 1) was transferred to the extraction chamber. The most suitable temperature for removing oil from soil was $260{ }^{\circ} \mathrm{C}$ in this study. The reactor pressure was kept above the vapor pressure (at the respective temperature) being $8 \mathrm{MPa}$ and the water was in a liquid state and its extraction time was 90 minutes. The water was quickly pumped at a rate of $15 \mathrm{ml} / \mathrm{min}$ until the desired temperature reaches the extraction cell (60 minutes). Afterward, the flow rate was increased to $40 \mathrm{ml} / \mathrm{min}$ and kept constant during the experiment (90 minutes). After full water extraction, the remaining TPH in the soil was measured by the remaining soil extraction with dichloromethane. The oil and wastewater phases achieved from the oil separation tank and the wastewater reservoir were separated by a separation funnel and then the oil separated from the oil layer was measured and analyzed as recycled oil. The concentration of TPH in the oil layer and the aqueous phase were analyzed.

The SWE method presented in this study is known as a desirable candidate for the treatment of solid fatty wastes. After 90 minutes of extraction at $260^{\circ} \mathrm{C}$ in a water-to-oil ratio of 3: 1, the removal efficiency was about $86 \%$ and oil recovery was about $39 \%$. After 90 minutes extraction at $260^{\circ} \mathrm{C}$ in a water-to-oil ratio of 3: 1, the Recovered oil had a higher level of density and specific gravity than commercial crude and had similar levels of elements and amounts of heat. After the extraction, there was a significant decrease in TPH content in soil residues. In summary, this research has found notable results in the field of oil removal and recovery and 
indicated the feasibility of using the SWE technique, which can be an effective and plausible way to restrain hazardous, highly moist, contaminated soils (Figure 8).

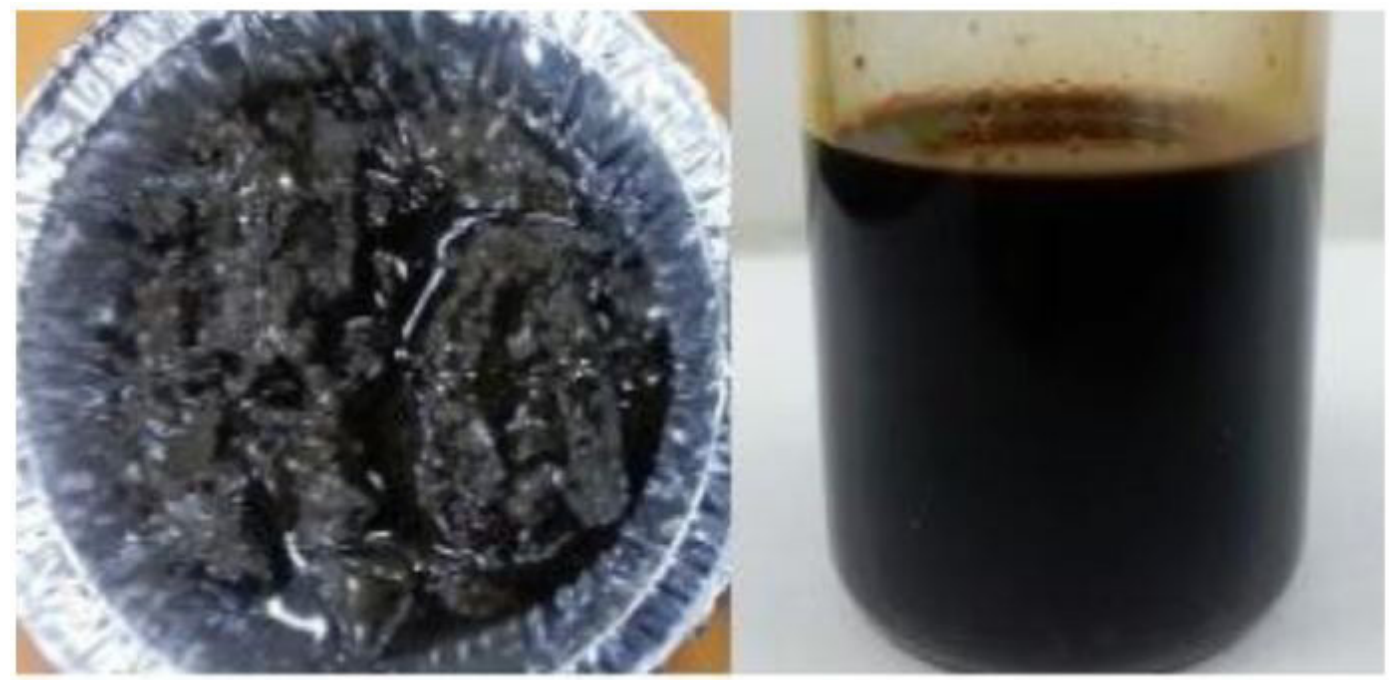

Figure 8: Oil samples and covered oil samples

\section{Correction of oil-contaminated soils using Dynamic SCWE and Static-dynamic SCWE methods}

The present study shows the static-dynamic and dynamic state of subcritical water extraction [45]. Extraction of subcritical liquid at high temperature and pressure uses liquids which are still in a liquid state and kept under the critical point. Subcritical water extraction (SCWE) is a green technology that uses heated water $\left(100\right.$ to $\left.374^{\circ} \mathrm{C}\right)$ at a pressure above $22.1 \mathrm{MPa}$ to maintain it in liquid form [25]. At high temperatures, hydrogen bonding forces between water molecules weaken and the dielectric constant and polarity are reduced [46]. So, subcritical waters approve the hydrophobic nature and act as organic solvents (Gan et al., 2009). Lubricant oil materials were used at relatively low temperature using SCWE [47]. The SCWE process is also used to clean infected PHC soils. The effect of temperature and time on SCWE has been investigated on lubricating oil from contaminated soil, where the extraction efficiency depends on temperature [48]. The soil sample was weighed and transferred to the extraction chamber located inside the thermal chamber. Afterward, the extraction chamber was closed and connected to the flow of water and pollution. Subsequently, the water was pumped out with a flow for a given period of time between the preheating coil and the extraction chamber (Figure 9).

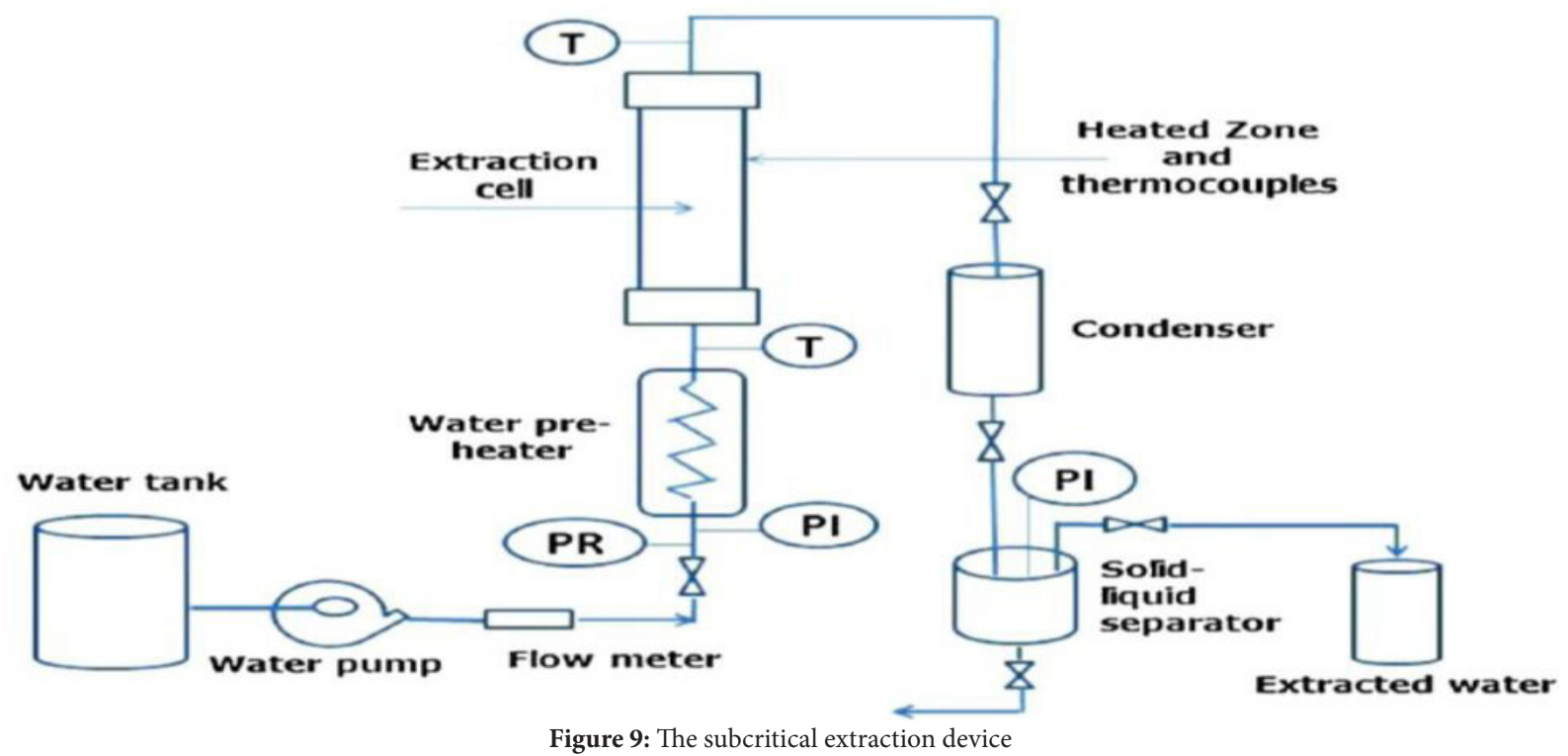

Dynamic method: $12 \mathrm{~g}$ of soil sample was placed inside the extraction chamber. A laboratory device was used for this method. After assembly, the extraction chamber was filled with water at a flow rate of $1 \mathrm{ml} / \mathrm{min}$ (thus the system was pressurized at $6 \mathrm{MPa}$ ), and the heater was turned on. When the temperature inside the chamber reached $100{ }^{\circ} \mathrm{C}$, the outlet valve with the flow rate of 0.3 $\mathrm{ml} / \mathrm{min}$ was activated to increase the temperature inside the cell to the desired level $\left(275^{\circ} \mathrm{C}\right)$. When the temperature in the chamber reaches the set temperature, the extraction time counting begins and then the dynamic extraction is performed by pumping water at $1 \mathrm{ml} / \mathrm{min}$ during the desired extraction time $(120 \mathrm{~min})$. 
Dynamic-static Method: The conditions are as follows for laboratory and pilot tests:

$12 \mathrm{~g}$ of soil was placed in the extraction chamber for dynamic extraction ( $360 \mathrm{~g}$ for extraction with a 30 -fold scale), the device is filled with water when the outlet valve is closed (thus the system is under pressure of $6 \mathrm{MPa}$ ) and the heater is turned on, When the internal temperature of the cell reached $100{ }^{\circ} \mathrm{C}$, the outlet valve is opened and flowed at a flow rate of $0.3 \mathrm{ml} / \mathrm{min}(9 \mathrm{ml} / \mathrm{min}$ for extraction at a 30-fold scale) to increase the temperature inside the chamber to the desired value; when The temperature inside the enclosure reached $275{ }^{\circ} \mathrm{C}$ and the system pressure reached $6 \mathrm{MPa}$, the static extraction stage was carried out for 15 minutes by closing the inlet and outlet valves. After this time period, both the outlet and inlet valves are opened and the high-pressure pump is turned on. Water flowed through the system at a rate of $1 \mathrm{ml} / \mathrm{min}(30 \mathrm{ml} / \mathrm{min}$, if extracted at 30 times scale to maintain water residence time inside the Extraction chamber).

The study indicates that the static-dynamic mode has a significant effect on extraction efficiency. The time and volume required for a dynamic static mode are much lower than those required for the dynamic mode. These results are practical in the development of subcritical water extraction technology for the extraction of lubricating oils widely used in soils contaminated with hydrocarbons. The work of Islam et al (2013) shows an increase in the SCWE temperature from 200 to $275{ }^{\circ} \mathrm{C}$ in $\mathrm{MPa}$, which reduces the TPH level in the oil contaminated soil by 3.5 times. This is related to the decrease in the dielectric constant and the surface tension of the subcritical water, which reduces polarization of water and increases oil dissolution. The optimal subcritical water extraction has been reported at $275^{\circ} \mathrm{C}$ [49]. The Further works Company improved the efficiency of removing the lubricating oil by more than $98 \%$ at $275^{\circ} \mathrm{C}$ by using static dynamic extraction in 120 minutes in a laboratory and also extracting 150 minutes in 30 times larger scale test by the same author the next year [48]. The change from static to static-dynamic mode increases the internal diaphragm distribution and mass transfer, which causes further increase in the efficiency of the elimination. Extraction of PAH-contaminated sand by subcritical water at different temperatures has been studied [50]. An efficiency of about $80 \%$ was reported regardless to extraction time, with the exception of naphthalene, with an improvement of about $35 \%$ when the extraction time increased from 1 to 20 hours. Decreasing dielectric constant and surface tension of subcritical water with increasing temperature will cause significant dissolution of non-polar organic compounds in water. Improved oil removal from contaminated soil is also dependent on time. The results of the effect of the influential parameters on extraction indicated that the extraction of lubricant from soil is strongly dependent on temperature and time. Comparing the two modes of SCWE (dynamic and static-dynamic) represents the $100 \%$ extraction efficiency of the TPH in the static-dynamic approach and 52\% efficiency for a dynamic approach. Therefore, we can point out that $99 \%$ of lubricating oils Can be extracted using the process introduced in this study using subcritical water.

\section{Pilot Scale subcritical water use to correct Soil Contaminated with Poly-aromatic Hydrocarbons and Pes- ticides}

The present study aimed to investigate the extraction of subcritical water at temperatures of $250{ }^{\circ} \mathrm{C}$ in $8 \mathrm{~kg}$ of soil contaminated with $70-70 \mathrm{mg} / \mathrm{kg}$ of each of trifluralin, atrazine, cyanazine, pendimethalin, alachlor, metolachlor and pesticides, which removes them to an unrecognizable degree [49].

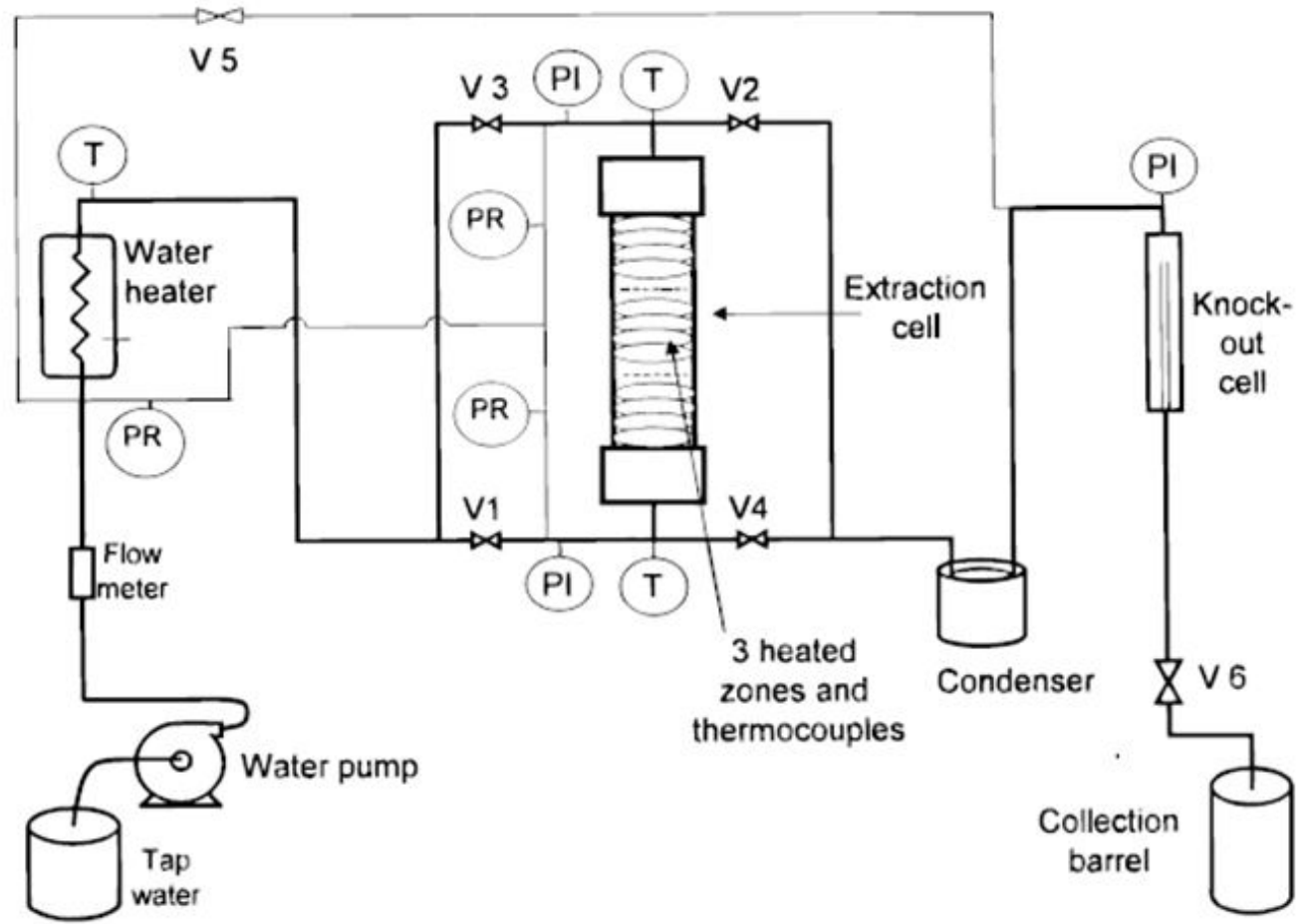

Figure 10: Pilot treatment Unit (8kg); V1 to V6: Valves; PI: Pressure Indicator; T: Thermocouple; PR: Pressure Release Valve 
Laboratory-scale system: Water is pumped through a low-flow preheater cycle $(0.1 \mathrm{~mL} / \mathrm{min})$ to fill the cavity from bottom to top. Toluene is pumped through the second pump for collecting extracted organic substances at a flow rate of $0.3 \mathrm{ml} / \mathrm{min}$. The pressure is adjusted to $50 \mathrm{bar}$ (for extraction at $250{ }^{\circ} \mathrm{C}$ or lower) or $100 \mathrm{bar}$ (for extraction at $275^{\circ} \mathrm{C}$ ) and the oven is heated to the desired temperature. The flow is kept constant through the pump at $0.1 \mathrm{ml} / \mathrm{min}$ until the oven reaches the desired temperature and the system pressure is manually controlled. After reaching the desired temperature, the water flow rate increases to the desired amount $(0.5$ or $1 \mathrm{ml} / \mathrm{min})$ and the toluene stream begins. The Analyte/toluene water mix flows and exits through the cooling coil and is collected in $20 \mathrm{ml}$ glass bottles. During extraction, both the water and toluene pumps operate in steady flow mode and the system pressure (usually at a favorable 5 bar pressure) is maintained by manual adjustment of the output value of the system.

System on the pilot scale: the setting is designed for operation at various temperatures from 100 to $300{ }^{\circ} \mathrm{C}$, at a maximum pressure of 105 bar and in a water flow of 0.1 to 1 liter per minute. $8 \mathrm{~kg}$ of soil is poured into the extraction cell. The water is pumped at about $570 \mathrm{ml} / \mathrm{min}$ to start filling the inner area. After leaving the reactor, the lid was closed, the outlet valve was closed, and the electric heaters installed on the extraction cell are turned on. After 1 hour of preheating (at that time, the internal temperature of the soil was $150{ }^{\circ} \mathrm{C}$, placed by the thermocouples at the center of the radial top and bottom of the soil column), the propane heater was turned on and the water flow began. The flow of water is controlled by the pump and the system pressure is controlled manually by adjusting the outlet valve. Sewage is collected periodically and analyzed after methylene chloride extraction. Afterward, the system was cooled for 4 hours and then three soil samples were collected (bottom, center, and top of soil column) and analyzed to determine the removal efficiency (Figure 10).

The results show that experiments on a laboratory scale ( $8 \mathrm{~g}$ of soil) are used to determine the state of the pilot scale ( $8 \mathrm{~kg}$ of soil). The extraction of PAH (2200 ppm total PAHs including naphthalene to benzoperylene) from contaminated soil with $275^{\circ} \mathrm{C}$ water, with high and low molecular weights achieve a detectable level (less than $0.5 \mathrm{ppm}$ ) in less than 35 minutes.

\section{Hot water extraction at wet oxidation site: The kinetics of removing PAHs from the soil}

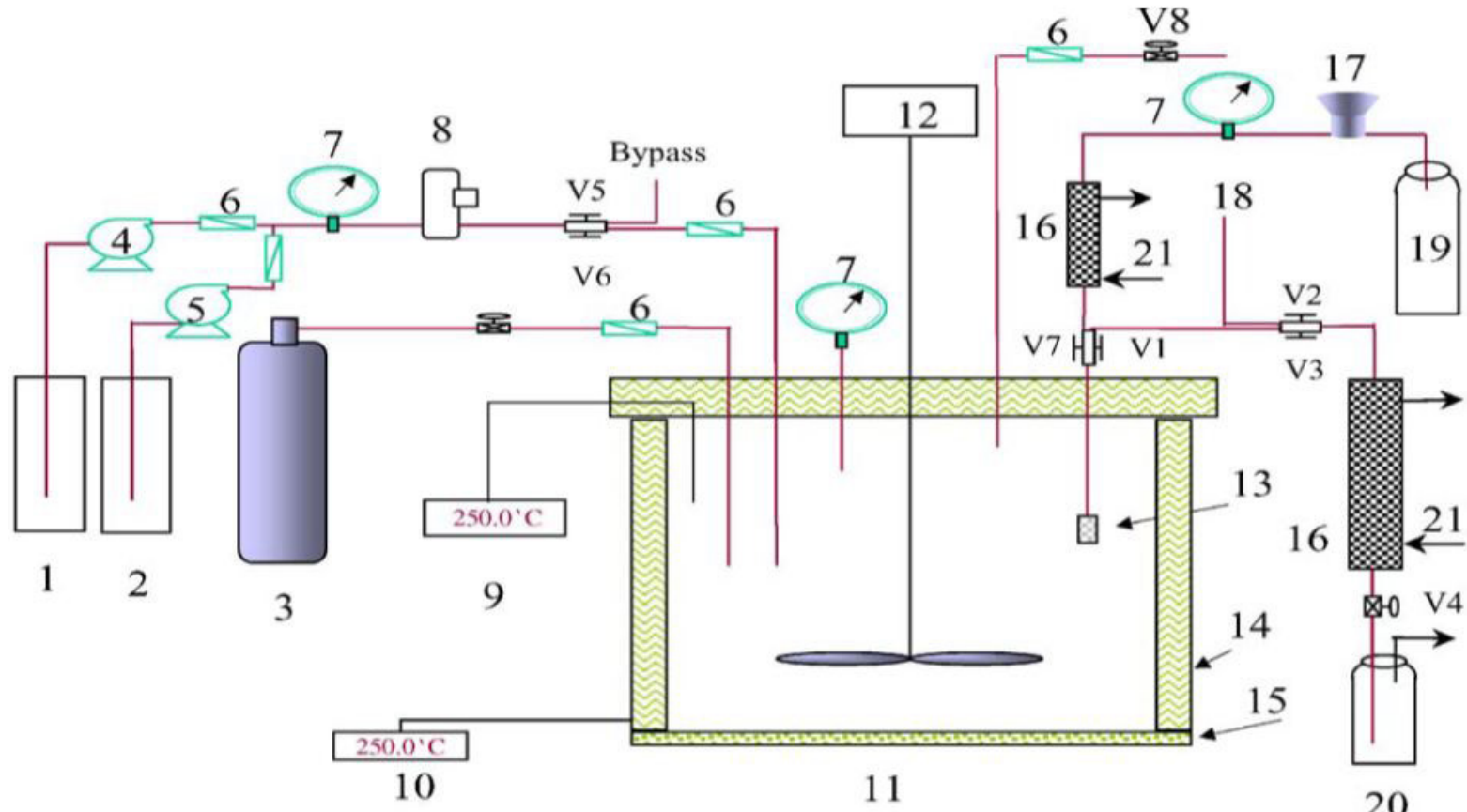

1- Water Container

2- Hydrogen Peroxide Solution

3- Nitrogen Cylinder

4- Pump 1

5- Pump 2

6- Check Valve

7- Pressure Gauge

8- Pressure Relief Valve

9- Thermocouple Thermometer

10- Temperature Control Unit
11- 300-mL Autoclave Reactor

12- Magnetic Stirrer

13- Metal Filter

14- Jacket Heater

15- Insulator

16- Heat Exchanger

17- Back Pressure Regulator

18- Washing Solvent Port

19- Water Collection Container

20- Sample Collection Vial
21- Cooling Water

V1 Sample Route Valve

V2 Washing Port Valve

V3 Sampling Valve

V4 Second Sampling Valve

V5 Water Bypass Valve

V6 Water Inlet Valve

V7 Continuous Flow Valve

V8 Vent Valve

Figure 11: The basic design for continuous flow experiments

In this study, a small-scale semi-continuous extraction with and without oxidation solution as the removal factor in the PAHs contaminated soil using subcritical water (for example, liquid water at high temperature and high pressure, but Less than the critical point) is addressed. Experiments were carried out in a 300-ml reactor using a soil sample [51] (Figure 11). Healthy natural 
soil samples that were contaminated with PAHs were screened with mesh 40 (420-micrometer holes). Double distilled water was used as extraction medium, Acceleration solvent extraction (ASE), acetone $99.99 \%$ for cleaning equipment, nitrogen gas from compressed cylinders for the initial pressure of the extraction chamber, and diluted aqueous solution of hydrogen peroxide (30\%) as the oxidation agent.

$10 \mathrm{~g}$ of soil sample which was extracted by ASE and analyzed by GC. $50 \mathrm{~g}$ of soil is added to the reactor and 200-220 ml of double distilled water is added to the top of the soil to reduce the dead volume. For extraction without oxidation, the reactor is pressurized with nitrogen, while an oxidizing agent (air, oxygen, or hydrogen peroxide) is needed in oxidation extraction. In hot water extraction, the reactor reaches a peak pressure of 450-400 psig of nitrogen. Hot water extraction with oxidation is fundamentally similar to warm water. An oxidizing agent is added to the water/ soil instead of nitrogen. Oxidizing agents include air, oxygen and hydrogen peroxide. As using air or oxygen, the amount of soil in the reactor to create the additional oxygen atmosphere required for oxidation of PAH is slightly lower. In case of hydrogen peroxide, with the same soil/water ratio as before, a portion of water with a volume equivalent to $30 \%$ hydrogen peroxide is replaced. All extraction and oxidation experiments are carried out at 250 ${ }^{\circ} \mathrm{C}$. To find isotherms and oxidation adsorption reactions, semi-continuous experiments with residence times of 1 and 2 hours at $250{ }^{\circ} \mathrm{C}$ and hydrogen peroxide as an oxidizing agent was performed. The experiment conditions are in hot water extraction and which combined with the oxidizing agent.

The results showed that in combined extraction and oxidation experiments, the remaining PAHs in the soil after the experiments were almost undetectable. In the combination of extraction and oxidation, after the first 30 minutes of experimentation, no PAH is detected in the liquid phase. Based on these results, hot water extraction, if combined with oxidation, reduces the cost and is considered as an alternative method that can be used to treat contaminated soils. PAH removal from the crushed soil in extraction experiments was only $79 \%$ to $99 \%$ dependent on the molecular weight of PAH. This composition for extraction and oxidation was $99.1 \%$ to higher than $99.99 \%$. While only about $100-28 \%$ of extracted PAHs are in the water phase, the oxidation extraction reduces this amount to a maximum of $10 \%$. Based on these results, hot-water extraction, if combined with oxidation, probably reduces the cost of water treatment and can be used as an appropriate alternative method to soil and contaminated sediments treatment.

\section{Supercritical water extraction}

Restoration of polycyclic aromatic hydrocarbons from soil using supercritical water extraction: The extraction study (SWE) aims to remove polycyclic aromatic hydrocarbons (PAHs) including naphthalene, phenanthrene, anthracene, and pyrene from contaminated soil [52]. Prior to using distilled water, is cleaned for 30 minutes with nitrogen to remove its oxygen (Figure 12).

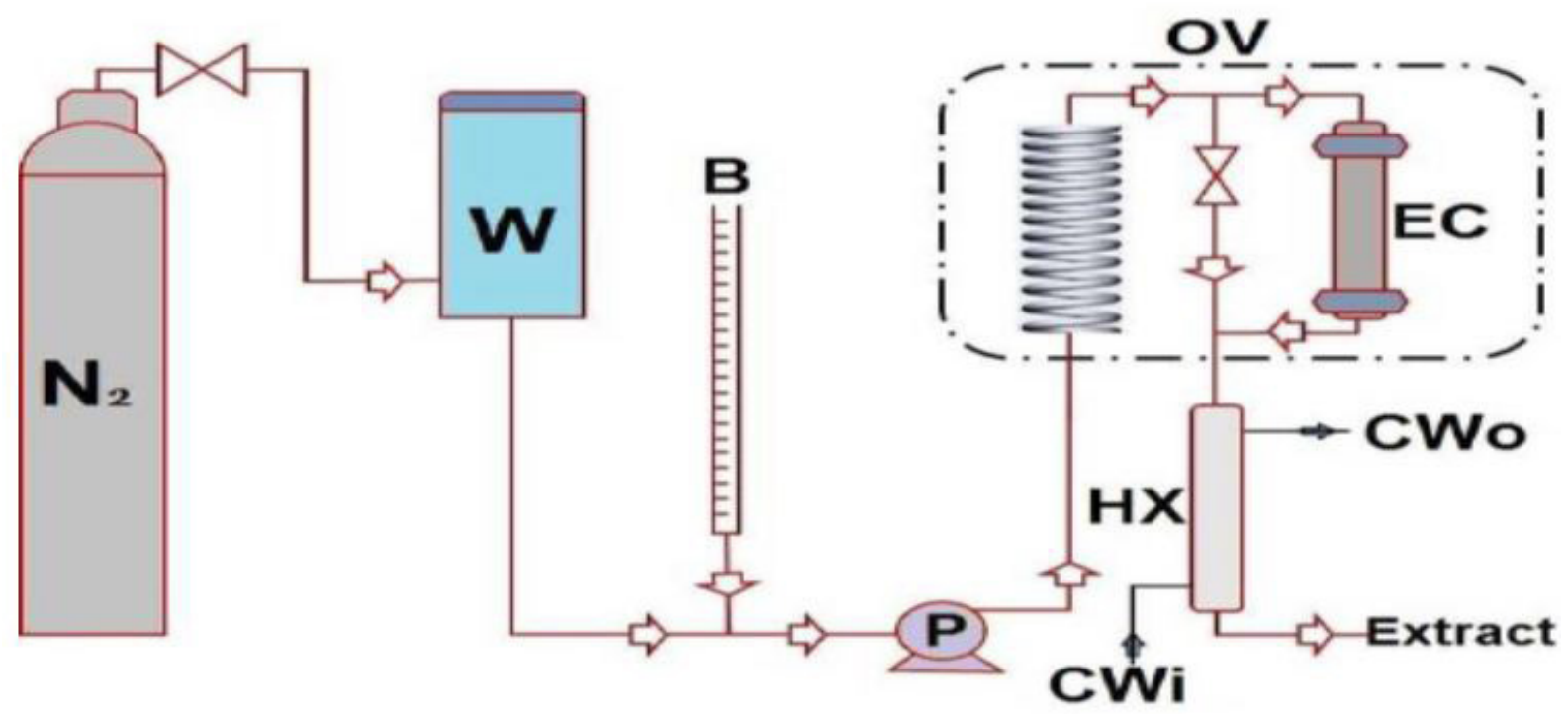

Figure 12: The supercritical water extraction system diagram; OV: Furnace; HX: Heat exchanger; EC: Extraction chamber; W: Water storage; CWi: Cooling water; CWO: Cooling the water; B: Burette

The pump operates at constant pressure. The steel extraction chamber is filled with $5 \mathrm{~g}$ of contaminated soil and water. The extraction chamber is located in the oven. The pump is switched on and the pressure is raised up to 20 bar. Then, the pump is switched off and oven temperature is increased to the desired value, the pump is switched on again and the flow is adjusted at the required rate. The water passes through the top-to-bottom in extraction chamber. When the temperature of the extraction chamber reaches the desired point, the extraction time begins. At the end of the extraction time, the oven and the pump are turned off and the pressure is adjusted to atmospheric pressure. For UV analysis, the pure soil is collected to verify the efficiency of SWE.

The results showed that the removal efficiency strongly depends on the water temperature. The effects of the two parameters of water and extraction time in purification efficiency were investigated. The water temperature varied from 100 to $180{ }^{\circ} \mathrm{C}$ and the extraction time was from 5 to 20 minutes. 


\section{Single-stage correction of soil contaminated by sludge using supercritical water extraction along with oxidation}

Supercritical water oxidation is an emerging technology that uses the supercritical properties of water as a reactant. The result of the lower product is clean soil with below $200 \mathrm{ppm}$ contamination level, and the top product is a gas stream of $\mathrm{CO}_{2}$ and water. Oxidation in supercritical water is a relatively new combustion process that uses water in the supercritical state as a reaction of medium and high-pressure oxygen as an oxidizing agent [53] (Figure 13).

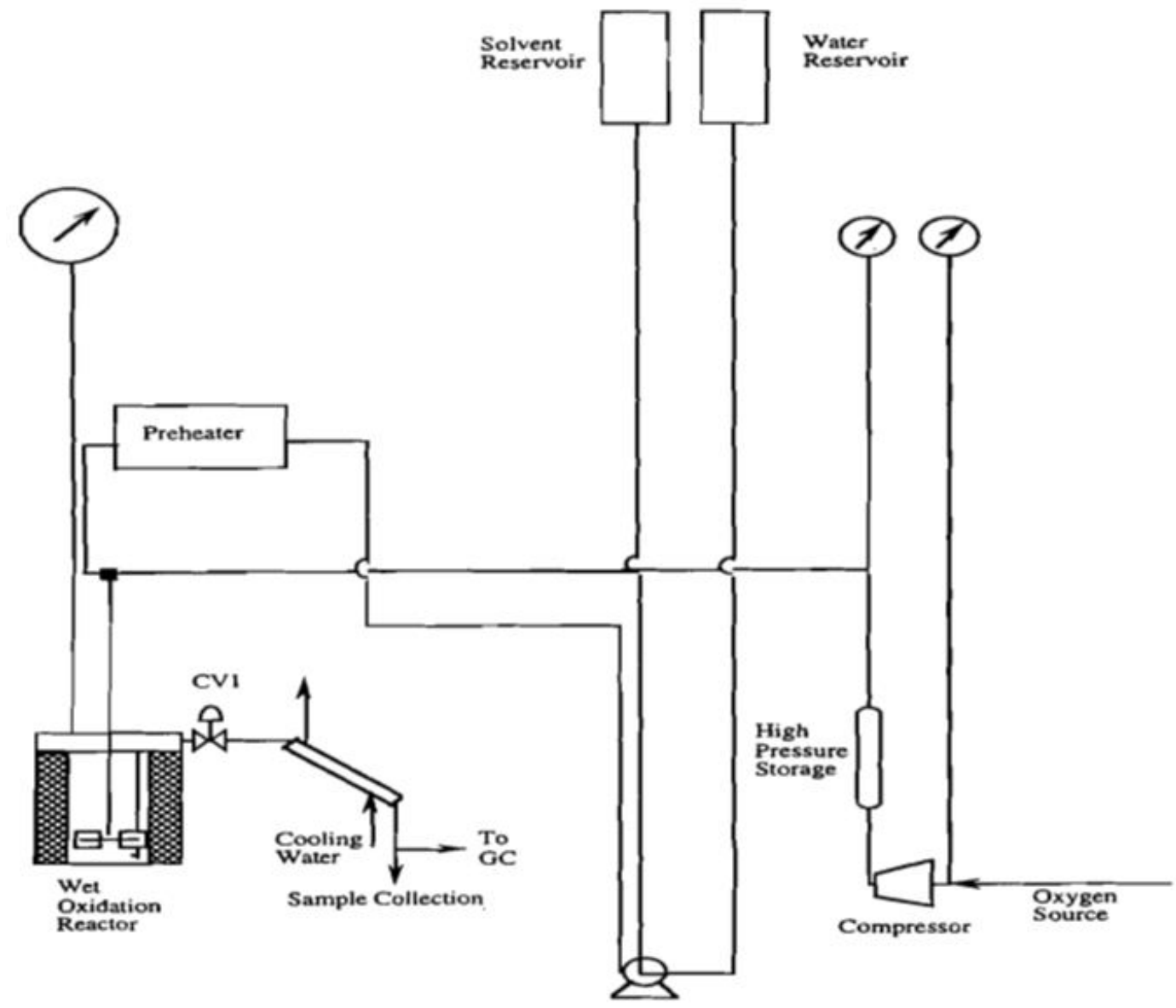

Figure 13: Minimal Pilot device for Supercritical Water Oxidation

The experiments were started by filling the reactor with $20 \mathrm{~g}$ of soil sample. When the temperature and pressure in the oxidation vessel reaches the desired supercritical conditions, $400{ }^{\circ} \mathrm{C}$ and $23.4 \mathrm{MPa}$, the solvent flow rate reduces. When the degradation conditions are achieved, oxygen enters the reactor. Oxygen velocity varied at three levels of $0.09,0.5 \mathrm{and}^{1} \mathrm{~cm}^{3} / \mathrm{min}$. After the oxidation reaction, the system is cooled and its pressure is reduced for collecting soil.

The results showed that supercritical water oxidation was able to eliminate $99.5 \%$ of hydrocarbon contaminants present in the soil. The supercritical water oxidation of PAH-infected soil is a suitable alternative to conventional processes as a full one stage treatment.

\section{Destruction of PAHs from the soil using hot pressurized water extraction along with supercritical water oxidation}

Hazardous organic wastes, including chlorinated hydrocarbons, in aqueous media containing salts, can be effectively oxidized by treatment above the critical point of pure water $\left(374{ }^{\circ} \mathrm{C}, 221 \mathrm{bar}\right)$. High destruction efficiencies may be achieved at low reactor residence times (approximately 1 minute or less) for temperatures above $550^{\circ} \mathrm{C}$. Under these conditions, no NOx.

Compounds are produced. The high solubility of organics and oxygen and the low solubility of salts in supercritical water make it an attractive medium for both oxidation and salt separation.

Oxidation carried out in a supercritical water environment at temperatures above $374{ }^{\circ} \mathrm{C}$ and pressures above $221 \mathrm{bar}(22.1 \mathrm{MPa})$ provides a viable method for the efficient destruction of organic wastes in a fully contained system. This patented process has been termed supercritical water oxidation, SCWO, and has been under commercial development for about the past 11 years by MODAR, Inc. [54-60]. The process has also proven suitable for treatment of human metabolic wastes and is being considered for 
use in life support systems on long-term spaceflights [61-64]. A relatively recent variation of SCWO involves carrying out the process in a deep well utilizing the hydrostatic head of fluid in the wellbore to help provide the necessary pressure level [65].

Economic predictions for SCWO have appeared in literature such as (for example, see Thomason and Modell); Stone and Webster Engineering Corp [66]; and Modell [67]. Due to the evolving nature of the technology and the inherent uncertainties associated with orders-of-magnitude scale-up from pilot-sized units to commercial-sized systems, these studies should be viewed with reservation. Earlier reviews of SCWO technology by Freeman [68], Modell [67] and Thomason et al. [59], while providing important basic process engineering material, need to be updated with respect to current process development and fundamental research on SCWO. A more recent paper by Shaw et al. [69] introduces several aspects of research related to reaction chemistry in supercritical water. In the supercritical water oxidation (SCWO) process water, organics, and oxygen gather together at moderate temperatures ( $400{ }^{\circ} \mathrm{C}$ and above) and high pressures (about $25 \mathrm{MPa}$ ). Under these conditions, a single fluid phase reaction system exists where many of the inherent transport limitations of multi-phase contacting are absent. The temperatures are high enough to induce spontaneous oxidation of the organics and the heat of reaction raises the mixture temperature to levels as high as $650{ }^{\circ} \mathrm{C}$. $\mathrm{Above}$ about $550{ }^{\circ} \mathrm{C}$, organics are oxidized rapidly and completely to conversions greater than $99.99 \%$ for reactor residence times of 1 minute or less. Heteroatomic groups, such as chlorine, sulfur, and phosphorus, are oxidized to acids which can be neutralized and precipitated as salts by adding a base to the feed. For aqueous solutions containing between 1 and 20 wt $\%$ organics, supercritical water oxidation could be more economical than controlled incineration or activated carbon treatment and more efficient than wet oxidation [58]. With appropriate temperatures, pressures, and residence times, organics are oxidized completely to $\mathrm{CO}_{2}$, water, and molecular nitrogen, without formation of NOx compounds or other toxic products of incomplete combustion. Modell and co-workers [70] also destroyed problematic polychlorinated biphenyls (PCBs) and DDT at greater than 99.99\% efficiency without formation of dioxins. Cunningham et al. [71] and Johnston et al. [72] oxidized synthetic pharmaceutical and biopharmaceutical wastes and achieved $>99.99 \%$ destruction of total organic carbon and $>99.9999 \%$ destruction of thermophilic bacteria. Oxidation in supercritical water is not limited to aqueous organics. Biomass, sewage, and soil can be slurried and fed to the reactor as a two-phase mixture. Wastes with large particles or high solids content may need to be homogenized prior to treatment. In principle, any mixture of organic waste that can be pumped to high pressure is treatable by SCWO. Precipitated salts and other solids can be removed from the product stream, providing a clean, high-temperature, high-pressure energy source consisting almost entirely of $\mathrm{CO}_{2}, \mathrm{H}_{2} \mathrm{O}$, and NO. Heat can be recovered from the treated process stream and used to preheat the feed, or the stream can be used to generate steam for direct process use or electric power generation in a high-efficiency Rankine cycle. The heat of the oxidation reaction is thus partially recoverable and can be used to offset the cost of treatment. One of the main attributes of SCWO is its ability to oxidize rapid and complete a wide range of organic compounds in a reaction system that meets the concept of a "Totally Enclosed Treatment Facility”. Dilute aqueous wastes ranging from 1 to $20 \%$ organic content are particularly well-suited to SCWO processing. The scale of application is also adaptable, from portable benchtop or trailer-mounted units treating 1 to up to several thousand gallons of toxic waste per day, to large stationary plants capable of processing 10,000 to 100,000 gallons per day of waste with 8 to $10 \%$ organic content. In the present designs, additional air pollution abatement equipment is not needed. Nonetheless, solids removal and storage are necessary, and water effluent polishing units incorporating ion exchange may be needed to remove small concentrations of dissolved metal ions. Major drawbacks of SCWO are the high pressures required ( $>230$ bar) and the fact that corrosion at certain points in the process is significant. For some wastes, solids handling can also pose difficulties.

For extraction of PAHs and toluene from sea sand, refined hot, and supercritical water oxidation equipment are made and then oxidation is carried out using hydrogen peroxide [46]. Pressurized hot water extraction (PHWE) and supercritical water oxidation (SCWO) are techniques that use physical and chemical properties of hot water and pressure to treat solid and liquid wastes. For the extraction of (PAHs) from sea sand and a real soil sample and for the breakdown of compounds through oxidation with hydrogen peroxide, the PHWE and SCWO methods were used. Generally, the best extraction recovery was achieved at $300{ }^{\circ} \mathrm{C}$ with an extraction time of 20 minutes. Compounds with the highest molecular weight were harder to extract. In contrast to the Soxhlet extraction, PHWE has had a particular improvement, especially for low molecular weight compounds. The oxidation efficiency (PAHs conversion) increases with increasing oxidant concentration and reaction time. The PHWE-SCWO method improves the efficiency.

The stable solution of PAH, 99.8\% Toluene (to prepare solutions), Dried sea sand (solid with grain size of 0.1-0.3 mm), distilled deionized water (for extraction), aqueous solution of hydrogen peroxide $30 \%$ (As oxidizing agent), 99.8\% acetone (for washing equipment), the oxidant concentration varies from 5.6 to $112.6 \mathrm{~g} / 1$.

4.5 grams of sand is washed with acid and dried, poured into the tube, and $200 \mathrm{ml}$ of PAH solution is injected.

In the PHWE-SCWO test, the oven 2 was heated to the selected temperature $\left(385^{\circ} \mathrm{C}\right.$ or $425^{\circ} \mathrm{C}$ ) and the oxidant stream (pump 2 : $\mathrm{v}$ $=1.0$ or $2.0 \mathrm{ml} / \mathrm{min})$ is started before the start of the pump $1(\mathrm{v}=1.0 \mathrm{ml} / \mathrm{min})$ for the water supply. Then the temperature of oven 1 is set at 200 or $300{ }^{\circ} \mathrm{C}$ for extraction. In the PHWE method (without SCWO), water is pumped at $385^{\circ} \mathrm{C}$ instead of oxidant (pump

2). The extraction time was 20 or 40 minutes at the selected temperature. The total time for extraction at $200{ }^{\circ} \mathrm{C}$ was 8 minutes longer, and at $300{ }^{\circ} \mathrm{C}$, it was 18 minutes longer due to warming the oven 1 to the selected temperature (Figure 14). 


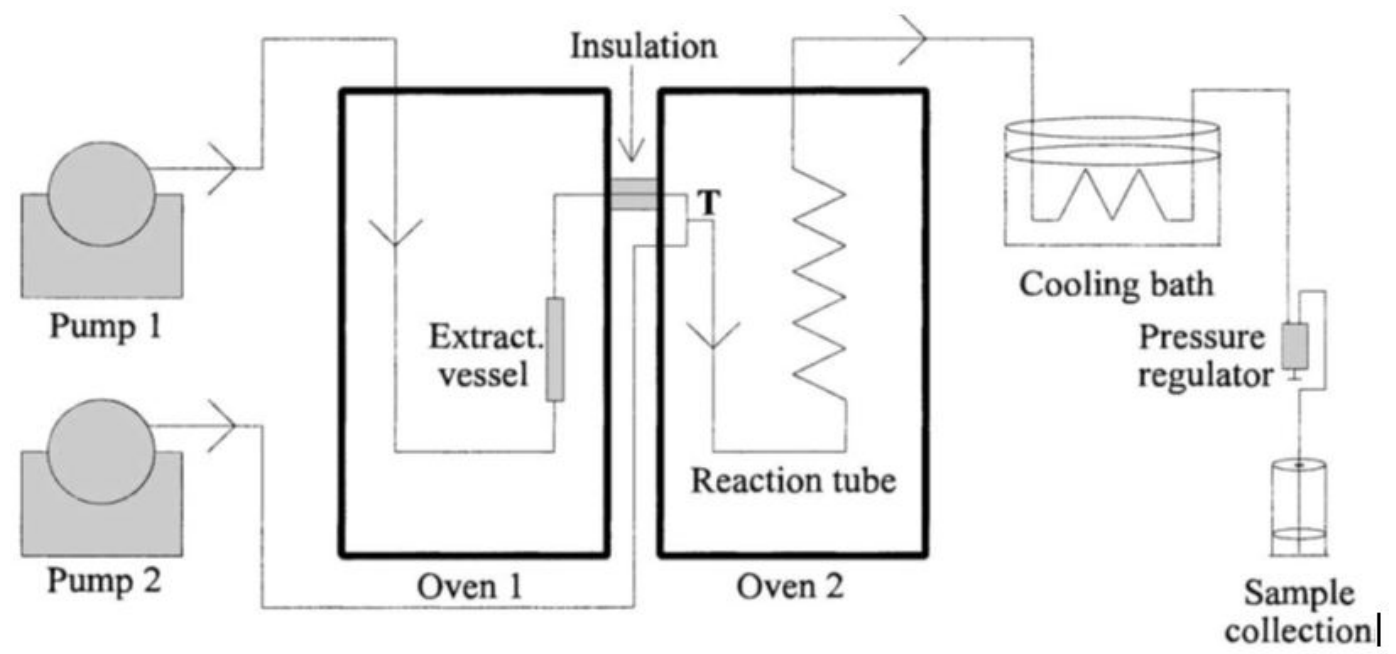

Figure 14: The PHWE-SCWO device

The results showed that the extraction efficiency increases with temperature and time; the best results were obtained at $300{ }^{\circ} \mathrm{C}$ with a 40 minute extraction time. In the oxidation stage, the conversion of PAHs increases with the reaction time and oxidant concentration, and the best conversion (97-99.9\% depending on the composition) is obtained at $425^{\circ} \mathrm{C}$ with a reaction time of 43 seconds and a concentration of $112.6 \mathrm{~g} / \mathrm{l}$. Benzaldehyde and benzoic acid are among the most frequent interveners in the oxidation process. In addition, phenol, proxy, and benzyl alcohol were found to be intermediates. Mediators consist mainly of toluene, which is present in the reaction medium at a higher concentration of PAHs.

\section{Extraction of polychlorinated biphenyls from soil under sub and supercritical general conditions}

Supercritical fluid extraction is a fast and efficient way to extract all kinds of organic compounds from a wide range of solids. Due to the highlighted change of temperature in polarity, water is an interesting alternative to $\mathrm{CO}_{2}$ as an extraction liquid. Many organic compounds are soluble enough to be extracted under subcritical conditions, and therefore problems, such as high corrosion of supercritical water and also technical problems can be avoided [73].

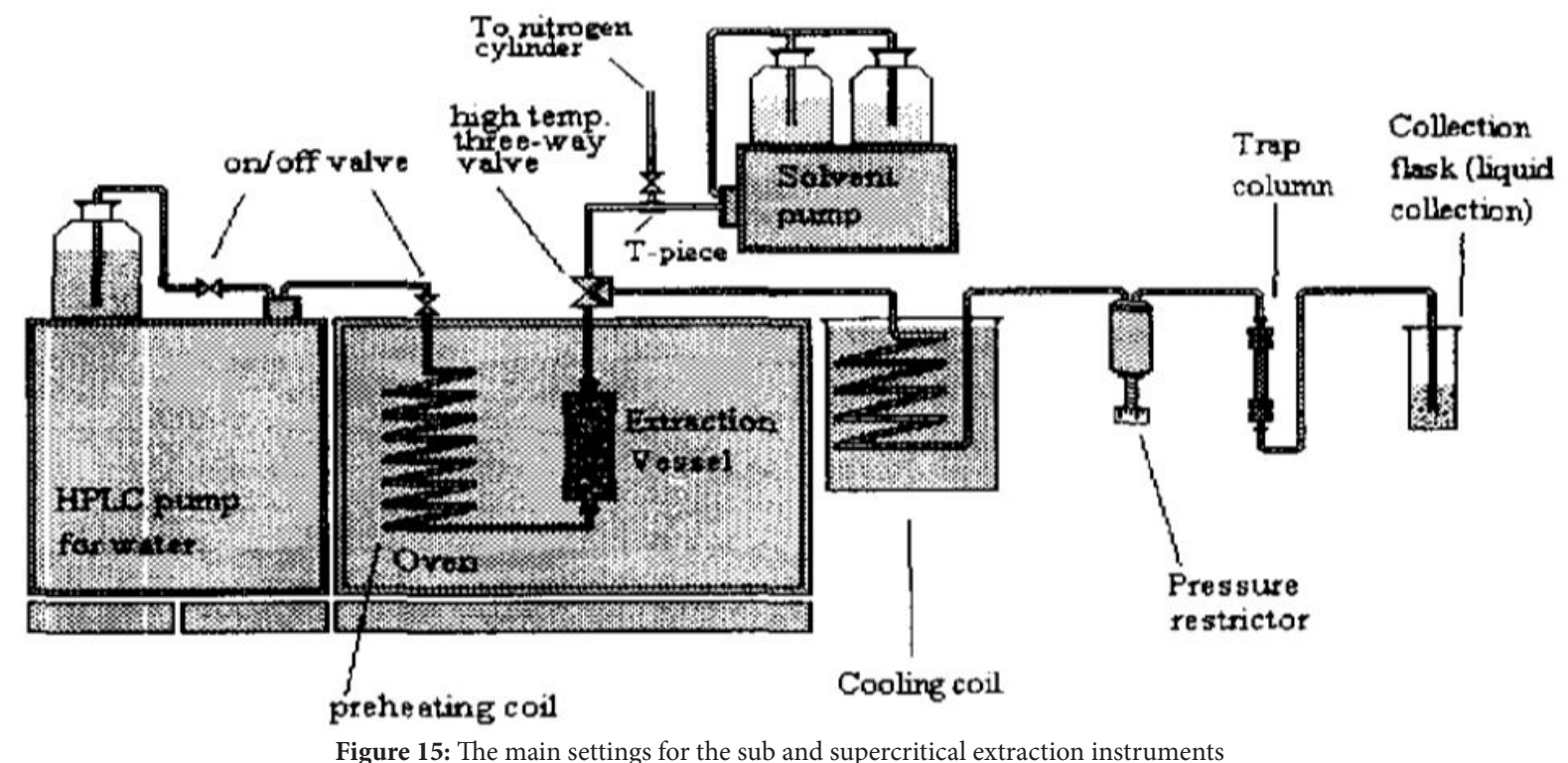

PCBs were filled with water in the extraction vessel along with sea sand, and the actual soil samples were placed in the extraction tank and filled up completely (pure sea sand was added to the $0.5 \mathrm{~g}$ soil sample). The water is placed in contact with the sample for 30 minutes at a flow rate of about $1 \mathrm{~mL} / \mathrm{min}$ with the super and subcritical pressure and temperature. During the extraction, the cooling coil was immersed in water at room temperature. After each extraction, the oven cools down. Where the solid phase valve is used, the valves and tubes are dried with nitrogen prior to washing with $\mathrm{n}$-heptane or other molecules $(1 \mathrm{ml} / \mathrm{min}) \mathrm{inside}$ the GC glass. In liquid duct, tubes are washed with $n$-heptane and combined with the water extract. The analytes were extracted from aqueous extracts with several parts $(5 \times 2 \mathrm{ml})$ of $\mathrm{n}$-heptane, concentrated using nitrogen and analyzed for GC. For each extraction, columns and valves of the column (if used) are washed with $10 \mathrm{ml}$ of nitrogen and $10 \mathrm{ml}$ of acetone and finally dried with nitrogen. The best result from the removal of PCBs in most cases (considering the different conditions of subcritical and supercritical temperatures and the proportional pressure) was more than $85 \%$ (Figure 15 ). 


\section{Summary and Conclusion}

The supercritical fluid process is always used to remove pollutants such as PHCs, PAHs, PCBs, dioxins, frances, phenols, chlorophenols, insecticides, metals and radioactive substances. The results have shown that the supercritical fluid method using $\mathrm{CO}_{2}$ has the ability to effectively eliminate organic and inorganic compounds in different contaminated soils [26].

Moreover, the cost of this method is acceptable compared to other available methods. On the other hand, the use of this method using water is more studied, as it is eco-friendly and has lower cost and better safety. Because of the high power of solubility, by using the PHWE method, various compounds can be extracted from different matrices at an acceptable temperature below the critical water temperature.

\section{Advantages of supercritical Fluid Extraction}

Compared to the conventional extraction processes using solvents, in this process, we can finally remove the pollutant from the solvent by changing the pressure and temperature. Also, its extraction time is lower than the conventional method, less solvent is consumed, less waste is produced and less toxic residues are left $[22,74,75]$. The solvent used in this method is easily recovered and can be used in subsequent extractions. In this method, less energy is consumed and the composition and structure of the soil are retained [76]. Compared to the biological processes, this process is faster and more efficient [76,77].

\section{Disadvantages of Supercritical Fluid Extraction}

Compared to the biological processes, this process requires the excavation, which increases the costs. This process can only remove pollutants from soil, and unlike the biological process, does not have the ability to degrade and convert pollutants into materials.

In developing this process, water was also used as an extraction fluid. However, the use of supercritical water is limited because of the high temperature (more than $374{ }^{\circ} \mathrm{C}$ ) and pressure (more than 218 atmospheres) and equipment corrosion. Therefore, the use of subcritical water extraction (SWE), known as pressurized hot water extraction (PHWE), is easier. In the PHWE method, while the water temperature rises from $100{ }^{\circ} \mathrm{C}$ to $274^{\circ} \mathrm{C}$, Hydrogen bonds between water molecules weaken and the dielectric constant of water is reduced. This reduces the polarity of water molecules [78]. Subcritical water, therefore, is more likely to absorb organic compounds than water in environmental conditions. Research has also shown that the SWE method has a better performance in extracting PAHs. The combination of the SWE process with the oxidation process by adding oxidizing agents like air, oxygen, hydrogen peroxide, etc. improves the extraction process in this method [75,78].

\section{References}

1. Conan G (1982) The long-term effects of the Amoco Cadiz oil spill. Phil Trans R Soc Lond B 297: 323-33.

2. Page DS, Foster JC, Fickett PM, Gilfillan ES (1988) Identification of petroleum sources in an area impacted by the Amoco Cadiz oil spill. Mari Pollut Bull 19: 107-15.

3. Paine RT, Ruesink JL, Sun A, Soulanille EL, Wonham MJ, et al. (1996) Trouble on oiled waters: lessons from the Exxon Valdez oil spill. Annual Review of Ecology and Systematics 27: 197-235.

4. Bragg JR, Prince RC, Harner EJ, Atlas RM (1994) Effectiveness of bioremediation for the Exxon Valdez oil spill. Nature 368: 413-8.

5. Lim MW, Lau EV, Poh PE (2016) A comprehensive guide of remediation technologies for oil contaminated soil-present works and future directions. Mar Pollut Bull 109: 14-45.

6. El-Sheshtawy HS, Khalil NM, Ahmed W, Abdallah RI (2014) Monitoring of oil pollution at Gemsa Bay and bioremediation capacity of bacterial isolates with biosurfactants and nanoparticles. Mar Pollut Bull 87: 191-200.

7. Gao Y-C, Wang J-N, Guo S-H, Hu Y-L, Li T-T, et al. (2015) Effects of salinization and crude oil contamination on soil bacterial community structure in the Yellow River Delta region, China. Applied Soil Ecology 86: 165-73.

8. Hentati O, Lachhab R, Ayadi M, Ksibi M (2013) Toxicity assessment for petroleum-contaminated soil using terrestrial invertebrates and plant bioassays. Environ Monit Assess 185: 2989-98.

9. Kanarbik L, Blinova I, Sihtmäe M, Künnis-Beres K, Kahru A (2014) Environmental effects of soil contamination by shale fuel oils. Environ Sci Pollut Res 21: 11320-30.

10. Ma J, Shen J, Liu Q, Fang F, Cai H, et al. (2014) Risk assessment of petroleum-contaminated soil using soil enzyme activities and genotoxicity to Vicia faba. Ecotoxicology 23: 665-73.

11. Tang J, Wang M, Wang F, Sun Q, Zhou Q (2011) Eco-toxicity of petroleum hydrocarbon contaminated soil. J Environ Sci (China) 23: 845-51.

12. Ramadass K, Megharaj M, Venkateswarlu K, Naidu R (2015) Ecological implications of motor oil pollution: earthworm survival and soil health. Soil Biology and Biochemistry 85: 72-81.

13. Broman D, Ganning B, Lindblad C (1983) Effects of high pressure, hot water shore cleaning after oil spills on shore ecosystems in the Northern Baltic proper. Mar Environmental Research 10: 173-87.

14. Lau EV, Gan S, Ng HK (2010) Extraction techniques for polycyclic aromatic hydrocarbons in soils. Int J Analyt Chem 10.1155/2010/398381.

15. U.D.o. Health H. Services (1995) Agency for toxic substances and disease registry, Toxicological Profile for Polycyclic Aromatic Hydrocarbons (PAHs),(update) PB/95/264370. Atlanta: US Department of Health and Human Services, USA.

16. M. Diphare, E. Muzenda, Remediation of Oil Contaminated Soils: A review, International Conference. On Chemical Integrated Waste Management and Environmental Engineering, Johannesburg, 2014, pp. 180-184. 
17. IARC Working Group on the Evaluation of Carcinogenic Risks to Humans (2010) Some non-heterocyclic polycyclic aromatic hydrocarbons and some related exposures. IARC Monogr Eval Carcinog Risks Hum 92: 1-853.

18. Hawthorne SB, Grabanski CB, Martin E, Miller DJ (2000) Comparisons of Soxhlet extraction, pressurized liquid extraction, supercritical fluid extraction and subcritical water extraction for environmental solids: recovery, selectivity and effects on sample matrix. J Chromatogr A 892: 421-33.

19. Yang Y, Belghazi M, Lagadec A, Miller DJ, Hawthorne SB (1998) Elution of organic solutes from different polarity sorbents using subcritical water. Journal of Chromatography A 810: 149-59.

20. Krukonis VJ (1994) Supercritical fluid extraction: principles and practice. Butterworth-Heinemann, Germany.

21. Erkey C, Madras G, Orejuela M, Akgerman A (1993) Supercritical carbon dioxide extraction of organics from soil. Environ Sci Technol 27: $1225-31$.

22. Akgerman A (1993) Supercritical fluid extraction of contaminants from environmental matrices. Waste Management 13: 403-15.

23. Tomasko DL, Macnaughton SJ, Foster NR, Eckert CA (1995) Removal of pollutants from solid matrices using supercritical fluids. Separation science and technology 30: 1901-15.

24. Hawthorne SB, Grabanski CB (2000) Correlating selective supercritical fluid extraction with bioremediation behavior of PAHs in a field treatment plot. Environ Sci Technol 34: 4103-10.

25. Gan S, Lau EV, Ng HK (2009) Remediation of soils contaminated with polycyclic aromatic hydrocarbons (PAHs). J Hazard Mater $172: 532-49$.

26. Anitescu G, Tavlarides L (2006) Supercritical extraction of contaminants from soils and sediments. The Journal of supercritical fluids 38: 167-80.

27. Morselli L, Setti L, Iannuccilli A, Maly S, Dinelli G, et al. (1999) Supercritical fluid extraction for the determination of petroleum hydrocarbons in soil. Journal of Chromatography A 845: 357-63.

28. Low GK, Duffy GJ (1995) Supercritical fluid extraction of petroleum hydrocarbons from contaminated soils. TrAC Trends in Analytical Chemistry 14: 218-25. 29. Al-Marzouqi AH, Zekri AY, Jobe B, Dowaidar A (2007) Supercritical fluid extraction for the determination of optimum oil recovery conditions. Journal of Petroleum Science and Engineering 55: 37-47.

30. Geranmayeh A, Mowla A, Rajaei H, Esmaeilzadeh F, Kaljahi JF (2012) Extraction of hydrocarbons from the contaminated soil of Pazanan II production unit by supercritical carbon dioxide. The Journal of Supercritical Fluids 72: 298-304.

31. Thiele-Bruhn S, Brümmer G (2005) Kinetics of polycyclic aromatic hydrocarbon (PAH) degradation in long-term polluted soils during bioremediation. Plant and soil 275: 31-42.

32. Moretto LM, Silvestri S, Ugo P, Zorzi G, Abbondanzi F, et al. (2005) Polycyclic aromatic hydrocarbons degradation by composting in a soot-contaminated alkaline soil. J Hazard Mater 126: 141-48.

33. Kulik N, Goi A, Trapido M, Tuhkanen T (2006) Degradation of polycyclic aromatic hydrocarbons by combined chemical pre-oxidation and bioremediation in creosote contaminated soil. J Environ Manage 78: 382-91.

34. Li J, Pignatello JJ, Smets BF, Grasso D, Monserrate E (2005) Bench-scale evaluation of in situ bioremediation strategies for soil at a former manufactured gas plant site. Environ Toxicol Chem 24: 741-9.

35. Wang J-Y, Stabnikova O, Lee SS, Tay J-H (2004) Integrated chemical-biological remediation for polycyclic aromatic hydrocarbons contaminated soil. Practice Periodical of Hazardous, Toxic, and Radioactive Waste Management 8: 79-83.

36. Tabak HH, Lazorchak JM, Lei L, Khodadoust AP, Antia JE, et al. (2003) Studies on bioremediation of polycyclic aromatic hydrocarbon-contaminated sediments: Bioavailability, biodegradability, and toxicity issues. Environ Toxicol Chem 22: 473-82.

37. Kamali H, Ghaziaskar H (2010) Pressurized hot water extraction of benzoic acid and phthalic anhydride from petrochemical wastes using a modified supercritical fluid extractor and a central composite design for optimization. The Journal of Supercritical Fluids 54: 16-21.

38. Ghoreishi S, Shahrestani RG (2009) Subcritical water extraction of mannitol from olive leaves. Journal of Food Engineering 93: 474-81.

39. Sheibani A, Ghaziaskar HS (2008) Pressurized fluid extraction of pistachio oil using a modified supercritical fluid extractor and factorial design for optimization. LWT-Food Science and Technology 41: 1472-7.

40. Sheibani A, Ghaziaskar HS (2009) Pressurized fluid extraction for quantitative recovery of aflatoxins B1 and B2 from pistachio. Food Control 20: 124-8.

41. van Bavel B, Rappe C, Hartonen K, Riekkola M-L (1999) Pressurised hot water/steam extraction of polychlorinated dibenzofurans and naphthalenes from industrial soil. Analyst 124:1351-4.

42. Islam MN, Jo Y-T, Park J-H (2012) Remediation of PAHs contaminated soil by extraction using subcritical water. Journal of Industrial and Engineering Chemistry 18: 1689-93.

43. Yang Y, Hildebrand F (2006) Phenanthrene degradation in subcritical water. Analytica Chimica Acta 555: 364-9.

44. Yang Y, Hawthorne SB, Miller DJ (1997) Class-selective extraction of polar, moderately polar, and nonpolar organics from hydrocarbon wastes using subcritical water. Environ Sci Technol 31: 430-7.

45. Islam MN, YT. Jo, Park J-H (2014) Subcritical water remediation of petroleum and aromatic hydrocarbon-contaminated soil: a semi-pilot scale study. Water, Air, \& Soil Pollution 225: 2037.

46. Kronholm J, Kalpala J, Hartonen K, Riekkola M-L (2002) Pressurized hot water extraction coupled with supercritical water oxidation in remediation of sand and soil containing PAHs. The Journal of supercritical fluids 23 123-34.

47. Kim HS, Kweon JH (2010) Cleaning of lubricating products from machinery parts using subcritical water. KSCE Journal of Civil Engineering 14: 1-6.

48. Islam MN, Jo Y-T, Park J-H (2014) Remediation of soil contaminated with lubricating oil by extraction using subcritical water. Journal of Industrial and Engineering Chemistry 20: 1511-6.

49. Lagadec AJ, Miller DJ, Lilke AV, Hawthorne SB (2000) Pilot-scale subcritical water remediation of polycyclic aromatic hydrocarbon-and pesticide-contaminated soil. Environ Sci Technol 34: 1542-8.

50. Kronholm J, Kuosmanen T, Hartonen K, Riekkola ML (2003) Destruction of PAHs from soil by using pressurized hot water extraction coupled with supercritical water oxidation. Waste Manag 23: 253-60.

51. Dadkhah AA, Akgerman A (2006) Hot water extraction with in situ wet oxidation: Kinetics of PAHs removal from soil. J Hazard Mater 137: 518-26.

52. Khanjari Y, Eikani MH, Rowshanzamir S (2016) Remediation of polycyclic aromatic hydrocarbons from soil using superheated water extraction. The Journal of Supercritical Fluids 111: 129-34.

53. Kocher BS, Azzam FO, Lee S (1995) Single-stage remediation of contaminated soil-sludge. Energy sources 17: 553-63. 
54. Modell M (1982) Processing methods for the oxidation of organics in supercritical water, USA.

55. Modell M (1985) Processing methods for the oxidation of organics in supercritical water, USA.

56. Freeman HM (1989) Standard handbook of hazardous waste treatment and disposal.

57. Swallow KC, Killilea WR, Malinowski KC, Staszak CN (1989) The modar process for the destruction of hazardous organic wastes-field test of a pilot-scale unit. Waste Management 9: 19-26.

58. Thomason T (1990) The MODAR supercritical water oxidation process, Innovative Hazar-dous Waste Treatment Technology Series.

59. Thomason TB, MODELL M (1984) Supercritical water destruction of aqueous wastes. Hazardous Waste 1: 453-67.

60. Barner H, Huang C, Johnson T, Jacobs G, Martch M, et al. (1992) Supercritical water oxidation: an emerging technology. Journal of hazardous materials 31: $1-17$.

61. Timberlake SH, Hong GT, Simson M, M. Modell (1982) Supercritical water oxidation for wastewater treatment: preliminary study of urea destruction. SAE Technical Paper.

62. Hong GT, Fowler PK, Killilea WR, Swallow KC (1987) Supercritical water oxidation: treatment of human waste and system configuration tradeoff study. SAE Technical Paper.

63. Hong GT, Killilea WR, Thomason TB (1988) Supercritical water oxidation: Space applications, Engineering, Construction, and Operations in Space. ASCE pp 987-98.

64. SBIR (1991) Supercritical Water Reactor for Space Applications, Final Report, Phase I, NASA Contract No. NAS9-18473, USA.

65. E. Gloyna (1989) Supercritical Water Oxidation-Deep Well Technology for Toxic Wastewaters and Sludges, Oxydyne Corp, USA.

66. Tester JW, Holgate HR, Armellini FJ, Webley PA, Killilea WR, et al. (1993) Supercritical water oxidation technology: process development and fundamental research. ACS Publications pp 35-76.

67. Modell M (1990) Treatment of pulp mill sludges by supercritical water oxidation. Modell Development Corp, Framingham, MA, USA.

68. Wilmanns EG (1990) Supercritical water oxidation of volatile acids, MS Thesis, USA.

69. Shaw RW (1991) Supercritical water, Chem Eng News 23: 26-30.

70. Shanableh A, Gloyna EF(1991) Supercritical water oxidation-wastewaters and sludges. Water Science and Technology 23: 389-98.

71. Cunningham V, Burk P, Johnston J, Hannah R (1986) The MODAR Process: An effective oxidation process for destruction of biopharmaceutical by-products. AIChE Summer National Meeting, Boston, MA, Paper 45c.

72. Johnston JB, Hannah RE, Cunningham VL, Daggy BP, Sturm FJ, et al. (1988) Destruction of pharmaceutical and biopharmaceutical wastes by the MODAR supercritical water oxidation process. Nature Biotechnology 6: 1423-27.

73. Hartonen K, Inkala K, Kangas M, Riekkola M-L (1997) Extraction of polychlorinated biphenyls with water under subcritical conditions. Journal of Chromatography A 785: 219-26.

74. David F, Verschuere M, Sandra P (1992) Off-line supercritical fluid extraction-capillary GC applications in environmental analysis. Fresenius' journal of analytical chemistry 344: 479-85.

75. Saldana M, Nagpal V, Guigard S (2005) Remediation of contaminated soils using supercritical fluid extraction: A review (1994-2004). Environmental technology 26: 1013-32.

76. Alonso E, Cantero F, Garcia J, Cocero M (2002) Scale-up for a process of supercritical extraction with adsorption of solute onto active carbon. Application to soil remediation. The Journal of supercritical fluids 24: 123-35.

77. Marr R, Gamse T (2000) Use of supercritical fluids for different processes including new developments-a review. Chemical Engineering and Processing: Process Intensification 3: 19-28.

78. Manahan SE (2006) Environmental science and technology: a sustainable approach to green science and technology. CRC Press, USA. 